Invited Review Paper to be published in

IEEE Trans Plasma Sci.

\title{
Vacuum Arc Ion Sources: Recent Developments and Applications
}

\author{
Ian Brown ${ }^{1}$ and Efim Oks ${ }^{2}$
}

${ }^{1}$ Lawrence Berkeley National Laboratory, Berkeley, California 94720, USA

${ }^{2}$ High Current Electronics Institute, Russian Academy of Sciences, Tomsk, 634055 Russia

May 2005

Supported by the U.S. Department of Energy, Initiatives for Proliferation Prevention, Projects IPP-LBNL-T2-0110 and -0197, under Contract No. DE-AC03-76SF00098. 


\title{
Vacuum Arc Ion Sources: Recent Developments and Applications
}

\author{
Ian Brown ${ }^{1}$ and Efim Oks ${ }^{2}$ \\ ${ }^{1}$ Lawrence Berkeley National Laboratory, Berkeley, California 94720, USA \\ ${ }^{2}$ High Current Electronics Institute, Russian Academy of Sciences, Tomsk, 634055 Russia
}

\begin{abstract}
The vacuum arc ion source has evolved over the past twenty years into a standard laboratory tool for the production of high current beams of metal ions, and is now used in a number of different embodiments at many laboratories around the world. The primary application of this kind of source has evolved to be ion implantation for material surface modification. Another important use is for injection of high current beams of heavy metal ions into the front ends of particle accelerators, and much excellent work has been carried out in recent years in optimizing the source for reliable accelerator application. The source also provides a valuable tool for the investigation of the fundamental plasma physics of vacuum arc plasma discharges. As the use of the source has grown and diversified, at the same time the ion source performance and operational characteristics have been improved in a variety of different ways also. Here we review the growth and status of vacuum arc ion sources around the world, and summarize some of the applications for which the sources have been used.
\end{abstract}

Index Terms - Ion source, vacuum arc, cathode spot, metal ion beam, ion implantation 


\section{INTRODUCTION}

The defining characteristic of the vacuum arc ion source is its production of high current beams of metal ions. The metal plasma from which the ion beam is formed is produced by a vacuum arc discharge, and hence the name. Vacuum arc ion sources have been used primarily for ion implantation in material surface modification research, and for particle accelerator injection for fundamental nuclear physics research, and also for other fundamental and applied purposes. Beams have been produced from over 50 of the solid metals of the Periodic Table, with ion energy up to several hundred $\mathrm{keV}$ and with beam current up to several amperes. The source is usually repetitively pulsed with pulse length up to some milliseconds and duty cycle as high $10 \%$ or more, and operation of a dc embodiment has been demonstrated. In general the ions have low but multiply-ionized charge states. The mean charge state lies between $1+$ and $3+$ depending on the particular metal, but the charge states can be increased in a number of different ways.

The history of vacuum arc ion sources extends back to the 1940's, when attempts to use this approach for isotope separation were first made in the U.S. as part of the Manhattan Project during World War II [1]; the effort was abandoned, however, for reason having to do with arc instability. Research in the general area of vacuum arcs has a long and rich history in the Former Soviet Union (FSU) [2], where the development of vacuum arc based ion sources began in the late 1950's and early 1960's, led primarily by Plyutto and co-workers at the Sukhumy Physical Technical Institute in Georgia [3]. This early work was largely a demonstration of the basic concept of metal ion extraction from vacuum arc plasma. In the mid 1960's a kind of vacuum arc ion source was developed by workers in Ukraine for the production of beryllium ion beams with current up to $170 \mathrm{~mA} \mathrm{[4].} \mathrm{In} 1979$ Prewett and Holmes developed a carbon vacuum arc ion source at the University of Liverpool, U.K., to produce a low energy $\mathrm{C}^{+}$ion beam current of up to $0.5 \mathrm{~A}$ [5]. In the early 1980's Humphries and co-workers at the University of New Mexico embarked on an extensive investigation of the vacuum arc for production of ion beams for heavy ion fusion research application [6]-[8]. The vacuum arc ion source program at the Lawrence Berkeley 
National Laboratory (LBNL) was initiated in 1982 for the production of high current uranium ion beams for injection into the LBNL heavy ion synchrotron (the Bevalac) for fundamental heavy ion nuclear physics research, and later for ion implantation application. The LBNL sources, called "Mevva" (metal vapor vacuum arc) ion sources, were developed in a number of different directions, including embodiments with multiple-cathode assemblies, very large extractors, miniature sources, and a test dc version. This work has been described in detail [9],[10]. At virtually the same time, development of vacuum arc ion sources was initiated at the High Current Electronics Institute (HCEI) of the Russian Academy of Sciences, Tomsk. These sources (called "Diana" [11] and "Titan" [12]) played a significant role in the rapid growth of activity in the field throughout the FSU. A series of vacuum arc ion sources called "Raduga" was developed at the Nuclear Physics Institute of the Tomsk Polytechnic University [13],[14], and the "Tamek" sources were developed at the Tomsk Institute of Automatic Control Systems and then at the Applied Physics Institute, Sumy, Ukraine [15]. Programs were subsequently established in other world universities, institutes and laboratories. An historical review of the early development of vacuum arc ion sources has been given elsewhere [16].

Vacuum arc ion source development has led to improved performance in a number of important beam characteristics in recent years, and applications have grown. One critical beam parameter, for example, is the ion charge state spectrum; for many purposes there is a need for higher charge states than normally formed in the vacuum arc plasma. Following this need, several different approaches to increasing the vacuum arc ion charge states have been developed. Beam noise and pulse-to-pulse reproducibility are very important for particle accelerator application, and these characteristics have been improved vastly in work carried out at the Gesellschaft für Schwerionenforschung (GSI), Darmstadt, Germany; the vacuum arc ion source is now routinely used for high current metal ion injection into the heavy ion accelerators there. Reliable and longlifetime arc triggering is another important source feature, and good progress has been made in this direction also. 
Here we review and summarize the source performance improvements that have been accomplished, and describe some of the facilities that have been established at several laboratories around the world, outlining both the sources themselves as well as the scientific applications for which the equipment has been used.

\section{THE BASIC VACUUM ARC ION SOURCE}

The basic operating principles of the vacuum arc metal ion source can be described using the example of the LBNL Mevva II ion source [10], a simplified schematic of which is shown in Fig. 1. As for any plasma-based ion source, there are two basic parts - the vacuum arc plasma generator, and the ion beam extraction system. The cathode of the vacuum arc is a simple cylindrical rod (typically $5-10 \mathrm{~mm}$ diameter) of the material of interest, and the discharge is triggered by a high voltage pulse applied to a trigger electrode that surrounds the cathode, separated from it by a thin (about $1 \mathrm{~mm}$ or less) alumina insulator. A part of the metal plasma created at the cathode flows through the anode hole, of diameter about $1 \mathrm{~cm}$, and then through a drift space of several centimeters to the extractor grids. That part of the plasma that strikes the anode carries the current that keeps the plasma alight, while the plasma plume that streams through the central hole in the anode is used to form the ion beam.

The kind of beam formation electrodes (extractor grids) used can be chosen to suit the particular application, and a conventional multi-aperture, accel-decel configuration is simple and effective. A set of three circular grids is located appropriately with respect to the expanding plasma plume, with the first grid (nearest the plasma) at or near plasma potential, the middle grid typically several kilovolts negative with respect to ground so as to suppress the backflow of low energy electrons, and the third grid at ground potential. The first grid and the entire plasma generation part of the source are biased to high positive potential. The magnetic field coil shown in Fig. 1 is optional and is often omitted entirely. A modest longitudinal magnetic field in the arc region can be used to control the amount of plasma that is transported from the cathode to the 
extractor. In the absence of magnetic field, much of the plasma is lost to the walls; with an applied field of just a few hundred gauss, the radial plasma loss can be much reduced and a greater fraction of the plasma that is formed can be presented to the extractor and converted into ion beam.

Usually the source is operated in a repetitively pulsed mode, with pulse width $100-500 \mu$ s and repetition rate up to several tens or hundreds of pulses per second. The arc current is typically in the range 50-500 A, often conveniently supplied by an LC pulse line. The trigger pulse is usually of $\mathrm{O} / \mathrm{C}$ amplitude $\sim 10 \mathrm{kV}$ and duration $\sim 10 \mu$ s or more, supplying a peak current of a few tens of amperes trigger-to-cathode by a step-up transformer which also serves for high voltage isolation. The ion beam extraction voltage in typical operation is several tens of $\mathrm{kV}$ up to a maximum of about $100 \mathrm{kV}$ and might be either dc or pulsed.

The metal ion beam current can easily be as high as several amperes, and for very broad beam sources up to several tens of amperes [10], but for the usual arc parameters and extractor sizes (beam diameter about $1-10 \mathrm{~cm}$ ) the typical ion beam current might be $100-500 \mathrm{~mA}$.

The beam divergence is determined primarily by the extraction optics, and assuming that the extractor grids have been designed and fabricated reasonably, the extraction optics can be empirically matched to the plasma by variation of the plasma density via the arc current. For optimum extraction conditions (the "perveance match" condition), the beam divergence is typically about $3^{\circ}$ half-angle for uranium.

The vacuum arc ion source produces ions that are multiply ionized, and the charge state spectrum of the ion beam is important for most applications. The ions generated by the vacuum arc are in general multiply-stripped with a mean charge state of from 1 to 3 , depending on the particular metal species, and the charge state distribution can have components from $Q=1+$ to $6+$; thus the ion energy is greater than the extraction voltage by this same factor.

The source operation and performance have been described in detail elsewhere; see for example [10], [17]-[19]. 


\section{SOURCE PERFORMANCE IMPROVEMENTS}

\section{A. Ion Charge States}

As described in the preceding, the vacuum arc typically forms ions with a spectrum of charge states ranging from $1+$ up to a high of about $6+$ depending on the metal species employed [10], [20]. A number of techniques have been investigated for shifting the charge state spectrum upwards and have met with varying degrees of success. Increasing the plasma electron temperature in order to elevate the fraction of electrons in the energetic Maxwellian tail of the distribution is clearly a good general approach. Numerical simulations carried out by Anders [21] show that an increase in electron temperature of the cathode spot plasma of just 1 or $2 \mathrm{eV}$ can lead to a significant increase in the multiply charged ion fraction. Electron temperature is determined by arc power consumption; the higher the discharge power the higher electron temperature. Thus one avenue to higher charge states is to find conditions that lead to increased discharge voltage at fixed arc current. Several methods of this kind have been explored, including the use of a strong magnetic field in the arc discharge region [22], modification of the arc current pulse shape by adding high current spikes [23], and employing a double-step arc system [24]. Each of these methods has its advantages and disadvantages, and each method does indeed result in an increase in the ion charge state multiplicity by a factor of up to $2-2.5$, depending on the cathode material. We note that each of these methods works well within the limits described, but the methods cannot be combined to yield yet higher charge states because each approach influences the same vacuum arc parameters - i.e. the electron temperature via the arc voltage; thus when combined one cannot expect a multiplicative effect.

Another approach to increasing the ion charge states is the use of an additional, independent ionization mechanism for ion stripping. Transport of a high energy electron beam through the plasma is one such approach. In experiments described elsewhere [25], an electron beam with energy $20 \mathrm{keV}$ and current density up to $40 \mathrm{~A} / \mathrm{cm}^{2}$ provided a strong influence on the ion charge 
state distribution of the vacuum arc plasma and the extracted ion beam. Another method is the application of electron cyclotron resonance (ECR) heating of the vacuum arc plasma for additional ionization. One can view a hybrid device of this kind alternatively as an ECR ion source with vacuum arc plasma injection. Some preliminary investigations of an ECR-MEVVA device have shown the formation of high charge state, high current, metal ion beams [26]. From an ECR ion source perspective, this technique can be seen as an alternative to atomic ovens or laser ablation as a means for the introduction of high melting point metal "feedstock plasma" into ECR ion sources.

A more-or-less straightforward way of measuring the ion charge state spectrum of the ion beam formed by a vacuum arc ion source is provided by a time-of-flight system, and such systems are now in use at a number of vacuum arc ion source laboratories. The setup developed and used at HCEI, Tomsk, Russia, is shown in Fig. 2, indicating also the current spike and electron beam heating components. A review of ion charge state enhancement in vacuum arc ion sources has been reported [27].

\section{B. Beam Noise and Pulse Shape Reproducibility}

The basic mechanism of vacuum arc plasma formation is via explosive emission from microscopic sites on the cathode surface [28], leading in turn to a relatively high fluctuation level in plasma density and thus also in extracted ion beam current. That is, the vacuum arc ion source beam is inherently a relatively noisy beam, and the pulse-to-pulse reproducibility is not high. While for some applications, such as broad-beam ion implantation for material surface modification, this is not a concern, for other applications, such as for particle accelerator injection, it can be a severe drawback, and for this purpose it is highly desirable to develop methods for forming a quieter beam and improved pulse shape reproducibility.

Minimum beam noise level is found empirically [29][30] to occur when the extraction voltage and plasma density are optimally matched - the perveance match condition for optimum 
beam formation. Note that an increased gas pressure in the discharge gap and in the extraction region improves the beam quality, but this method shifts the CSD to lower charge states. There is also a significant influence of magnetic field on beam noise and pulse stability.

Humphries and co-workers developed a technique for reduction in ion beam noise level by the use of wire meshes to reflect plasma electrons and to limit pure ion flow by its own space charge [31]. In the case of space-charge-limited flow the extracted ion beam current is independent of the plasma fluctuation level and random plasma generation at the cathode spots. The method has been further developed specifically for accelerator injection application [32],[33].

Work carried out at GSI Darmstadt, Germany, over a period of several years has resulted in a vast improvement in both the beam noise and the beam pulse shape reproducibility [34]. By combining a number of techniques, including the use of meshes, addition of optimized magnetic field, and geometrical optimization, the performance of the GSI vacuum arc ion sources has been brought to the point where they are fully acceptable for routine accelerator injection application. The most recent such source has been called "Varis" (described below). The good performance of this source with respect to beam noise is evident from Figs 3. Fig 3(a) shows the pulse shape of a uranium ion beam, pre-analysis with all charge states, as measured by a Faraday cup $30 \mathrm{~cm}$ downstream; current is $156 \mathrm{~mA}$ and beam noise is $\pm 4 \%$. Fig. 3(b) shows the post-analysis $\mathrm{U}^{4+}$ beam as measured by a beam transformer at the entrance to the pre-LINAC RFQ accelerator, a point about $12 \mathrm{~m}$ downstream from the ion source; $\mathrm{U}^{4+}$ beam current is about $25 \mathrm{~mA}$ and beam noise is $\pm 5 \%$. The pulse shape, beam noise, and reproducibility are adequate for the Varis source to be used routinely at GSI for high current injection of metal ions into the accelerators.

\section{Triggering Lifetime}

Surface flashover across a ceramic insulator surrounding the cathode rod is the triggering method mostly commonly used for vacuum arc ion sources [10]. The reliability of the method can be improved if the surface of the insulator is slightly conductive; this occurs naturally after 
some arc operation since metal plasma and macro-particles (droplets) are deposited onto the insulator surface. In fact, operation with a new, clean, ceramic insulator can fail to trigger because the surface resistance may be too high for breakdown, and contaminating the insulator surface with a thin graphite layer (using an ordinary pencil) helps to get started. Extension to the limit of this thinking can lead to the kind of triggering described by Anders [35]. In this system no trigger electrode is present; instead, the surface of the insulator separating cathode and anode has a conducting surface layer. When the main arc circuit is switched on (by an additional high current switch in the arc circuit), current across the surface of the insulator causes the first cathode spot to be initiated on that edge of the cathode near the insulator. The high current switch can be a thyristor (SCR), high-current transistor, or other. This system has been called "triggerless" arc initiation, and has been used in vacuum arc plasma sources and ion sources for triggering lifetimes in excess of $10^{6}$ pulses [36].

A gaseous pre-discharge can provide another approach to cathode spot ignition in vacuum arc ion sources. In order to avoid the negative influence of background gas on the ion charge state distribution, a low pressure gas discharge should be used. Two closely related kinds of gaseous discharges that are suitable and that have been used for vacuum arc triggering are the Penning (which is used in the Titan-3 ion source, discussed in detail below) and the cylindrical magnetron discharges; both are $E \times B$ discharges. In both cases the electrons are confined by a strong magnetic field and so have a long lifetime within the discharge gap. For both systems the main arc is ignited between the cathode and the hollow anode of the gaseous discharge; the hollow cylindrical anode thus serves a dual purpose. A small solenoid coil is used in both cases to establish a magnetic field in the plasma region. With the same trigger pulse parameters as for the surface flashover method $(10 \mathrm{kV}, 10 \mu \mathrm{s})$, stable arc ignition can be obtained even for background pressure as low as $10^{-6}$ Torr. Operation for long lifetimes has been obtained by this approach, greater than $10^{6}$ pulses at a repetition rate of 50 pps. This approach has been described fully elsewhere [37]. 


\section{Gaseous Operation}

The vacuum arc ion source is above all a metal ion source. However it can be operated so as to form beams that are controllable mixtures of gas and metal ions. Gas is fed into the source near the arc region where the plasma density is high, and a modest magnetic field $(B \sim 200-400 \mathrm{G})$ is applied. The gas is ionized and gaseous ions are mixed with the metal plasma and extracted ion beam. The fraction of gaseous ions is regulated by the gas feed, and the gas-to-metal ion ratio can be controlled from zero to as much as about $99 \%$ gaseous. An example of this effect is shown in Fig. 4 for a titanium ion beam. In this case a magnetic field was added to the arc region, and thus the low pressure Ti charge states are elevated over the usual charge state distribution for the case of zero-B. As the pressure is increased, there is a slow downshift of metal ion charge states, and a simultaneous increase in the fraction of gaseous ions in the beam. Two conclusions follow from these kinds of observations: (i) high fractions of highly charged ions call for the lowest possible background gas pressure, and (ii) ambient gas pressure provides a means for controlling the ion charge state distribution toward lower states. These effects can be used to advantage. For example, hybrid Ti-N ion beams have application for implantation of sub-surface TiN layers, and similar buried ceramic layers can be formed from other species such as Al-O, Zr-O, etc. [38]. In work related to accelerator injection, a vacuum arc ion source was used to provide $\mathrm{Mg}^{+}$ions for injection into the GSI heavy ion accelerator, having increased the ion source gas pressure so as to maximize the fraction of singly-charged ions with respect to the doubly-charged $\mathrm{Mg}^{2+}$ fraction [39]. A way of operating a vacuum arc source in a 100\% gaseous mode has been reported [40]. In this case the vacuum arc feature is not used at all, but instead a hollow cathode glow discharge is formed in the same ion source geometry. There is a small gaseous contamination of the metal ion

beam even at the lowest pressures at which the vacuum arc ion source is normally operated $\left(\sim 10^{-6}\right.$ torr or less). The primary source of this is condensation of gas (oxygen, nitrogen, water vapor) on the fresh front surface of the cathode from the residual ambient between arc pulses. This also affects, to a small extent, the metal ion charge state distribution. The magnitude of the effect 
depends on the time between pulses, and can be minimized by operating at high repetition rate, greater than about $10 \mathrm{pps}[41]$.

\section{The Source as a ToOl for VAcuum Arc Plasma Physics}

The parameters of the extracted ion beam contain information about the parameters of the vacuum arc plasma from which the beam has been formed, including processes within the cathode spots that are the route origin of the metal plasma. Thus analysis of beam parameters such as ion current and charge state can provide a tool for investigation of phenomena in the vacuum arc plasma. Experimental investigation of the vacuum arc plasma is difficult because the cathode spots from which the plasma originates are small in size $\left(<10^{-2} \mathrm{~cm}\right)$, move randomly across the cathode surface with a velocity of $\sim 10^{4} \mathrm{~cm} / \mathrm{s}$, and the plasma density near the spots is $>10^{16} \mathrm{~cm}^{-3}$. In view of this difficulty, studies at a distance from the spots of the particles (here ions) formed, sometimes called "emission methods", provide an approach that can be used to study cathode spot phenomena experimentally.

The vacuum arc ion source in combination with a time-of-flight diagnostic for ion charge-tomass analysis provides an almost ideal system for investigation of the charge state spectra of ions produced in the vacuum arc plasma. This has been described in section III.A above, and we do not elaborate further on this important application of the experimental hardware. In the following we describe two further interesting applications of the use of a vacuum arc ion source as an experimental tool for the study of cathode spot plasma physics by emission methods.

\section{A. Vacuum Arc Ion Drift Velocity}

Ions formed in a vacuum arc plasma have a significant inherent drift velocity (also called directed ion velocity and ion streaming velocity), of order several $\mathrm{cm} / \mu$ s depending primarily on the metal ion species employed. Knowledge about the ion drift velocity is important from a 
fundamental perspective as well as for applications including plasma deposition of films and plasma immersion ion implantation. In experiments carried out to measure the ion drift velocity, the extractor grids were removed from the ion source and the plasma allowed to stream freely away from the arc region. The plasma drift speed was determined from the time for a density perturbation (density spike produced by a short current spike, or termination of the plasma pulse at the end of the arc current pulse) to propagate to a downstream Faraday cup. The experiments showed that ion drift velocity is charge-state-independent but varies according to the ion species used. The results are shown in Fig. 5, where the measured drift velocity is plotted as a function of the atomic number of the ion species (cathode material) investigated [42].

For comparison the predictions of two models are also shown. A two-fluid hydrodynamic model developed by Mesyats [43] considers a cathode flare of ions with mean charge state $\langle Q\rangle$ adiabatically expanding after explosive formation of an "ecton". The model predicts a plasma expansion velocity at large distance from the cathode spot given by

$$
v_{i}=\frac{2}{\gamma-1} \sqrt{\frac{\gamma\left(\langle Q\rangle T_{e}+T_{i}\right)}{M_{i}}},
$$

where $\gamma=5 / 3$ is the adiabatic exponent. Taking $T_{e} \approx T_{i}$ and substituting values for $\langle Q\rangle$ and $T_{e}$, the drift velocity can be estimated. The results are shown in Fig. 5 as the upper solid line. The good agreement of the model with experiment allows us to conclude that the mechanism responsible for ion drift is indeed a hydrodynamic mechanism

A modified hydrodynamic model [44] has been proposed to describe the observations, based on the idea that the cathode material is further accelerated after its transition to the fully ionized collisional plasma state, the origin of this additional effect being the plasma expansion into vacuum with continued Joule heating. This model predicts a plasma drift velocity given by

$$
v_{i}=3.5 \sqrt{\gamma\langle Q\rangle T_{e} / M_{i}},
$$

shown in Fig. 5 as the lower solid line [45]. The fit is seen to be excellent. 
Simulations have predicted that the velocities of variously charged ions can be different from their mean hydrodynamic velocity by only a few percent, and this agrees with the experimental data obtained. The measurement of ion drift velocities by emission methods has been described in greater detail elsewhere [46]-[48].

\section{B. Ion Erosion Rate}

The ion erosion rate is of fundamental importance not only to understanding of cathode spot physics but also to virtually all applications of the vacuum arc, including its use as an ion source. By erosion rate we refer here to the total ion current that is formed by and available from the metal plasma, expressed as a fraction of the arc current that is used to drive the vacuum arc plasma discharge. Experiments were performed using the LBNL Mevva V ion source [10], modified appropriately. One reason for choosing this ion source facility for these experiments is that in our analysis of vacuum arc phenomena we can integrate the erosion rate data with other data obtained on the same facility, such as ion charge state distribution [20], electron temperature [21], directed ion velocity [47], and burning voltage [48].

The Mevva V was modified as shown in Fig. 6. The usual ion source anode was replaced by a transparent anode made from fine stainless steel mesh; the mesh was spherical in shape with mesh openings $0.8 \mathrm{~mm} \times 0.8 \mathrm{~mm}$ and geometric transparency $60 \%$. The mesh anode was electrically insulated from the original ion source anode and extraction system. Both electrodes COL1 and COL2 were negatively biased to $-200 \mathrm{~V}$ with respect to the mesh anode, and thus both electrodes served as a large ion collector. When bias voltage was applied, plasma ions flowing through mesh holes were collected over the entire surface of electrodes COL1 and COL2. The arc supply was as used for ion source operation: arc current pulses of $250 \mu$ s duration with a flat-top amplitude up to $300 \mathrm{~A}$, at a repetition rate of several pulses per second.

The results of these experiments show that the ion erosion rate $\alpha_{i}=I_{\text {ion }} / I_{\text {arc }}$ varies according to the cathode material, from a low of $5 \%$ for tungsten to a high of $19 \%$ for carbon. These results 
can be taken as a refinement of the often-quoted value of about $10 \%$ [49]-[51]. The ion erosion rate experiments have been described in more detail elsewhere [52].

\section{SOME VACUUm ARC ION SOURCE FACILTIES}

\section{A. Mevva $V(L B N L$, Berkeley, USA)}

A number of vacuum arc ion sources have been developed at the Lawrence Berkeley National Laboratory (LBNL) [10], of which the broad-beam Mevva-V has evolved to be the most used. This source has been operated steadily for many years with infrequent need for maintenance or repair. It remains a reliable workhorse and has served as a basic model for vacuum arc ion sources elsewhere. A schematic of the source is shown in Fig. 7 and a photograph in Fig. 8.

This embodiment uses a $10 \mathrm{~cm}$ diameter, multi-aperture, accel-decel extractor configuration, incorporates an 18-cathode multiplex assembly, and can operate at up to about $65 \mathrm{kV}$ extraction voltage (absolute maximum is $100 \mathrm{kV}$ ). For optimum beam optics the plasma profile across the extractor aperture can be kept somewhat uniform by means of a samarium cobalt permanent magnet multipole structure located within the plasma expansion chamber [53], but this is not essential and has not normally been used. Source cooling was improved over that of earlier versions, and so also the mean power dissipation capability. Upgrades to the Mevva-V that have been incorporated over the years include the addition of a small high-field pulsed solenoid around the arc region for charge state control, and the addition of a gas feed inlet to the arc region for the formation of hybrid metal-gas ion beams [54]. Interestingly, we note that the Mevva-V ion source has been operated as a high current electron source by simply changing the source bias from positive to negative [55], without any other change to the setup. The LBNL Mevva V ion source is used for a variety of research purposes including exploration of vacuum arc phenomena [46],[52], ion implantation into metals [56], semiconductors [57] and optoelectronic materials 
[58], synthesis of high-Tc superconductors, some bioengineering experiments [59], heavy ion fusion [60], and other. This source has been fully described in [10], [30], [61], [62].

\section{B. Titan-3 (HCEI, Tomsk, Russia)}

The vacuum arc ion sources made and developed at the High Current Electronics Institute, (HCEI), Tomsk, Russia, were given the name "Titan". These sources were a parallel development to the Berkeley Mevva sources. The Titan sources have the very nice feature of being able to produce either metal or gas ion beams by using either of two different types of arc discharge - a vacuum arc (metallic) or a constricted arc (gaseous) - in the same discharge system. This allows the formation of near-surface layers in the implantation target material of metal-gas compounds with high strength characteristics. Metal ions are generated by operating in the usual vacuum arc mode. To generate gaseous ions, a constricted arc discharge with cold cathodes is used. In this kind of discharge, ions are produced in the cathode region from the cathode material, while plasma is generated in the anode cavity by ionization of the working gas. Several versions of the source have been developed, each with its own special features. The main application has been for metal surface modification to increase hardness, reduce wear and to enhance corrosion resistance.

A schematic of the Titan-3 ion source is shown in Fig. 9 and a photograph of the mounted source in Fig. 10. This source uses gas for the high voltage insulation, as opposed to oil insulation used in earlier versions; use of oil leads to carbon in the ion beam due to the diffusion of oil through various vacuum seals. Water cooling is used, and provision is made for electrical isolation (3 in Fig. 9) of the high voltage discharge chamber from the grounded cooling water supply unit. If distilled water is used, this decoupling ensures adequate high voltage hold-off and low leakage current for voltages up to $80 \mathrm{kV}$. Distilled water circulates in a closed loop. The arc current is $40-150 \mathrm{~A}$ and the pulse duration is $400 \mu \mathrm{s}$. The pulse repetition rate is variable over the range $10-50 \mathrm{~Hz}$. The extractor diameter is $15 \mathrm{~cm}$. Since the discharges for the metal plasma and the gaseous plasma have independent power supplies and the plasma generation processes are 
different and quite separate from each other, it is possible to produce a two-component metal-gas ion beam with the ion fractions in each component being readily controllable by variation of discharge currents. The ion beam current that can be formed ranges typically $0.1-0.3 \mathrm{~A}$ for gas ions and $0.2-0.5 \mathrm{~A}$ for metal ions. Over the past decade more then ten different versions of Titan ion source have been made and delivered to research laboratories in former Soviet Union countries and elsewhere (China, Poland). The Titan sources have been described in detail elsewhere [12],[63].

\section{Raduga (NPI, Tomsk, Russia)}

A series of vacuum arc ion sources were developed at the Nuclear Physics Institute (NPI) of the Tomsk Polytechnic University, given the name "Raduga" [14] (Russian for "rainbow"). The sources incorporated a number of novel features, including multiple cathodes between which the arc could be rapidly switched, thus generating beams alternating on a short timescale between various metal ions. In the same source the extraction voltage could also be controlled from pulse to pulse, thus offering the additional versatility of ion energy control of each of the different metal ion beams formed from each sub-cathode. By means of this rapid control of ion species and ion energy, it was possible to carry out ion implantation of multiple species with experimenterdetermined control of the implantation depths and so to achieve excellent overlap of the implantation profiles for each species.

In another source version [64], the arc cathode was a large rectangular block over which the cathode spots were guided magnetically; the arc source was operated dc. Cathodes with operating areas of 300 and $1500 \mathrm{~cm}^{2}$ were investigated. A macroparticle filter of novel design [65] was also included in the plasma drift region. A schematic of the plasma source is shown in Fig. 11. The extractor voltage was repetitively pulsed, with pulse duration $400 \mu$ s and repetition rate up to 50 pps. Because of the motion of the cathode spots on the large area cathode, the ion beam emission region on the extractor surface also moves, and on a long-term integrated basis a very broad beam 
ion source is effected. This source can be used for metal film synthesis with ion beam assisted deposition, as well as for straightforward ion implantation.

\section{The Izmir Mevva V (Turkey)}

The vacuum arc ion source program in Turkey was established by researchers led by Prof. A. Oztarhan at Dokuz Eylul University, Izmir, as a collaborative effort together with groups at LBNL, (Berkeley, USA), HCEI, (Tomsk, Russia), and ANSTO (Australian Nuclear Science and Technology Organization)(Sydney, Australia). The Izmir Mevva ion implantation system was commissioned in 1997. Fig. 12 shows a schematic of the electrical system used and Fig. 13 a photograph of the installation. The facility was built as a copy of the LBNL Mevva V ion source with upgrades including a magnetic coil and a gas feed as described in section III.D above. The arc power supply and triggering systems were designed and provided by ANSTO, and a time-offlight spectrometer for ion charge state measurement by HCEI.

The facility has been used for the surface modification of metals for increased hardness, corrosion resistance and reduced wear, and for some highly novel work on the modification of the surface properties of textile materials, including their flame retardant, water repellant, and wear and pilling characteristics. Cotton and polyester fabrics were investigated and improvements in these textile properties were obtained. The facility has been described in detail elsewhere [66].

\section{E. The BNU (Beijing Normal University) Mevva Sources (China)}

Beijing Normal University is a leader in the development of vacuum arc ion sources and implanters in China. The first such system was developed in 1987 with support from the National High Technology Research and Development Program of China. This embodiment was a single cathode version based on the Berkeley Mevva II source. To increase the source lifetime (meaning operational time period between necessary maintenance, mostly cathode replacement), a movable 
cathode was introduced that could be advanced axially to present new cathode material as the cathode is consumed in operation. Since then more than ten different embodiments of vacuum arc ion source based implanters have been developed and deployed in factories and companies in the Peoples Republic of China, Hong Kong and Taiwan, with increasingly impressive ion source and implantation parameters. Among these, the largest presently in use is the Mevva-50 implanter [66] with a time-averaged ion beam current of $50 \mathrm{~mA}$, installed at the Advanced Materials Center in the southern China city of Shenzhen. A photograph of this machine is shown in Fig. 14. Parameters of the BNU Mevva-50 implanter are given in Table I.

An even larger machine is presently under construction at BNU [67]. This is the Mevva-100 implanter with time-averaged ion beam current of $100 \mathrm{~mA}$. This metal ion implantation facility will be the largest vacuum arc metal ion implanter for industrial surface processing in the world. A photograph of the very large vacuum chamber with ion source attached is shown in Fig. 15, and some of the main device parameters are listed in Table II. With the large processing capacity of this implanter, the average cost for an implantation dose of $2 \times 10^{17}$ ions $\mathrm{cm}^{-2}$ will be lowered down to a few US cents per $\mathrm{cm}^{2}$ of implanted material. This low processing cost level could herald a breakthrough for the cost-sensitive industrialization of metal ion implantation.

The BNU Mevva ion implanters have been used for the surface modification of metals. TEM and XRD characterization has indicated the formation of dispersed nano-phases in the ion implanted layers. The depth of the modified layer is seen to be much greater than the corresponding ion range, and the atomic concentration of implanted metal in this layer can be as high as $25 \%$. The hardness and wear resistance increases greatly with increasing dose and ion flux, and the friction coefficient is reduced in most cases. The BNU research has also indicated that simultaneous co-implantation using dual or triple Mevva ion sources installed on the same machine produces even better results. The BNU vacuum arc plasma sources are also used for thin film deposition; details of this line of work have been described [68]-[70].

Vacuum arc ion sources have also been developed elsewhere in China. At Dalian Technology University, several high current metal ion implanters have been set up, including both Mevva and 
Titan types [71]. The source performance was improved by addition of an appropriately oriented magnetic field at the cathode to increase the arc spot mobility for uniform cathode erosion, leading to improved arc stability and increased cathode lifetime. A magnetic field produced by permanent magnets was added in the discharge region so as to reduce plasma from loss to the wall. The maximum time-averaged beam current of the metal ion implanter was measured to be up to about $30 \mathrm{~mA}$ at an accelerating voltage of $30 \mathrm{kV}$.

\section{F. The Nagasaki Mevva (Japan)}

A Mevva-based vacuum arc ion implanter is used at the Industrial Technology Center of Nagasaki, Japan, for the surface modification of cutting tools and other machine tools and components, and other metallurgical surface modification applications [72]. The design of the source is similar to Mevva IV, but with only 8 cathodes in the revolving multiple-cathode unit. The ion beam extraction voltage can be varied from $20 \mathrm{kV}$ to $80 \mathrm{kV}$. Peak pulsed ion beam current is $0.5 \mathrm{~A}$; the pulse length of $1 \mathrm{~ms}$ and pulse repetition rate of up to 20 pps give a timeaveraged ion beam current of up to $10 \mathrm{~mA}$ over the $15 \mathrm{~cm}$ diameter beam. A photograph of the implanter system is shown in Fig. 16.

\section{G. The GSI Source for Accelerator Injection (Darmstadt, Germany)}

Vacuum arc ion sources have been used successfully at the GSI heavy ion accelerator research center at Darmstadt, Germany, for injecting metal ions into a linear accelerator and synchrotron, including uranium. Much of this work was performed collaboratively with the HCEI, Tomsk, group. For accelerator application the quality of each individual ion beam pulse is important, as opposed to the case for ion implantation application. Beam noise and/or pulse shape variation from pulse to pulse can lead to poor accelerator performance. Thus this source has incorporated a number of the developments referred to in the preceding to enhance the high ion charge state 
fraction, to reduce the beam noise, and to improve the pulse-to-pulse beam shape reproducibility [32]-[34].

A schematic of a recent GSI source, the Varis, is shown in Fig. 17 and a photograph in Fig. 18. The cathode assembly holds 17 individual cathodes, each $17 \mathrm{~mm}$ long and $5.7 \mathrm{~mm}$ in diameter. The stainless steel anode is located a distance of $15 \mathrm{~mm}$ from the cathode and has a central aperture $15 \mathrm{~mm}$ in diameter. Magnetic field coils are located external to the vacuum chamber. Two stainless steel grids are installed to reduce the beam fluctuation level and to reduce plasma density. A multi-aperture accel-decel extraction system (13 holes, each $3 \mathrm{~mm}$ in diameter, aspect ratio 0.5 ) is used to form the ion beam. As an example of source performance, $25 \mathrm{~mA}$ of $\mathrm{U}^{4+}$ ion current with an energy of $2.2 \mathrm{keV} / \mathrm{u}\left(156 \mathrm{~mA}\right.$ full beam, or $170 \mathrm{~mA} / \mathrm{cm}^{2}$, electrical current) was measured at the entrance of the RFQ, for a typical extraction voltage of $32 \mathrm{kV}$, with a high fraction (67\% electrical current fraction) of $\mathrm{U}^{4+}$ ions, a post-analysis $\mathrm{U}^{4+}$ beam noise level of less than $\pm 10 \%$, and good beam pulse shape reproducibility. The main parameters of the GSI Varis ion source that are important for accelerator injection application are collected in Table III.

This ion source has proven its capability in extended tests at the GSI high current injector and has been put into regular operation for the generation of high current uranium ions for the GSI accelerator facility, providing uranium ion beams with current an order of magnitude greater than previously possible. We note that because of the fixed input velocity required to match into the RFQ $(2.2 \mathrm{keV} / \mathrm{u})$, the ion source extraction voltage and the post-acceleration must be changed for all the different ion species used; thus each new species needs to be independently optimized. The GSI sources have been described in detail elsewhere [73]-[75].

\section{CONCLUSION}

A widespread community of vacuum arc ion source developers and users has evolved, and a substantial body of literature in the field is growing. The primary application of the source has turned out to be for non-semiconductor ion implantation - surface modification of metals, 
polymers, and other materials; the source and beam parameters are well matched to the requirements. Large sources have been developed and incorporated into implanters, and inroads have been made into commercialization of the technology. The size of the implanters - physical dimensions, beam parameters, and surface processing rate - is impressive, and further increase still is technologically possible. Another application is for particle accelerator injection. Considerable research effort has been invested in the development of techniques for reduction of beam noise and improvement in beam pulse shape reproducibility, and this work has seen a high degree of success. A vacuum arc ion source is now routinely used for injection of metal ion beams, including uranium, into the GSI heavy ion synchrotron at record high current levels.

Further development could lead to better source performance and characteristics in a number of ways, including for example, improved triggering methods, extended source lifetime (between necessary down-time for cathode maintenance), high charge state elevation and control, and further reduction of beam noise, among other things. All of these needs are receiving experimental attention, and it is to be expected that the future will witness some exciting advances, as has the past.

\section{ACKNOWLEDGEMENTS}

We are grateful to our many friends and colleagues in the vacuum arc ion source community throughout the world for their generous provision of information about their facilities and their

future plans. This work was supported by the U.S. Department of Energy, Initiatives for Proliferation Prevention, Projects IPP-LBNL-T2-0110 and -0197, under Contract No. DE-AC03$76 \mathrm{SF} 00098$. 


\section{REFERENCES}

[1] R. K. Wakerling and A. Guthrie, Eds., Electromagnetic Separation of Isotopes in Commercial Quantities. USAEC, National Nuclear Energy Series, 1951, p. 324.

[2] I. G. Kesaev, Cathode Processes in Electric Arcs. Moscow: Nauka, 1968 (in Russian).

[3] A. A. Plyutto, "Acceleration of positive ions from the expanding plasma of a vacuum spark", JETP vol. 39, no. 6, p. 1589, 1960 (in Russian).

[4] E. I. Revutskii, G. M. Skoromnyi, Yu. F. Kulygin, and I. I. Goncharenko, "Pulsed heavy-ion source with solid working substance", in Proc. Soviet Conf. Charged-Particle Accelerators, Moscow, Oct. 9-16, 1968, A. A. Vasiliev, Ed., (transl. published by the USAEC), p. 447.

[5] P. D. Prewett and R. Holmes, "A vacuum arc source for $\mathrm{C}^{+}$ions", J. Phys. E: Sci. Instrum., vol. 12, no. 3, pp. 179-181, 1979.

[6] S. Humphries, Jr., M. Savage, and D. M. Woodall, "High current density plasma cathode", Appl. Phys. Lett., vol. 47, no. 5, pp. 468-470, 1985.

[7] C. Burkhart, S. Coffey, G. Cooper, S. Humphries, Jr., L. K Len, A. D. Logan, M. Savage, and D. M. Woodall, "Vacuum arc arrays for intense metal ion beam injectors", Nucl. Instrum. Meth. Phys. Res. B, vol. 10-11, pt. 2, pp. 792-795, 1985.

[8] S. Humphries, Jr., C. Burkhart, and L. K. Len, "Ion sources for pulsed high-brightness beams", in The Physics and Technology of Ion Sources, I. G. Brown, Ed., New York: Wiley, 1989, pp. 397-419.

[9] I. G. Brown, J. E. Galvin, and R. A. MacGill, "High current ion source," Appl. Phys. Lett., vol. 47, pp. 358-360, 1985.

[10] I. G. Brown, "Vacuum arc ion sources," Rev. Sci. Instrum., vol. 65, no. 10, pp. 3061-3081, 1994. 
[11] G. P. Badgenov, S. P. Bugaev, G. P. Erokhin, V. N. Kiselev, A. E. Ligatchev, S. M. Chesnokov, and A. V. Ianchiuck, "Metal ion source based on cold cathode vacuum arc", in Proc. 5th All-Union Symp. High Current Electronics, Tomsk, Part II, pp. 93-95 (1984) (in Russian).

[12] S. P. Bugaev, A. G. Nikolaev, E. M. Oks, P. M. Schanin and G. Yu.Yushkov, "The 'TITAN' ion source', Rev. Sci. Instrum., vol. 65, no.10, pp. 3119-3125, 1994.

[13] A. I. Ryabchikov, "Emission properties of broad-beam vacuum arc ion sources", Rev. Sci. Instrum., vol. 63, no. 4, pt. 2, pp. 2425-2427, 1992.

[14] A. I. Ryabchikov, S. V. Dektjarev, and I. B. Stepanov, "The metal vapor vacuum arc ion sources 'Raduga'", Rev. Sci. Instrum., vol. 65, no. 10, pp. 3126-3133, 1994.

[15] A. M. Tolopa, "Development of TAMEK and other vacuum arc ion sources," Rev. Sci. Instrum., vol. 65, no. 10, pp. 3134-3139, 1994.

[16] I. G. Brown and E. M. Oks, "Vacuum arc ion sources - a brief historical review", IEEE Trans. Plasma Sci., vol. 25, no. 6, pp. 1222-1228, 1997.

[17] I. G. Brown, "The metal vapor vacuum arc ion source", in The Physics and Technology of Ion Sources, I. G. Brown, Ed., New York: Wiley, 1989, Ch. 16.

[18] E. Oks and I. Brown, "Vacuum arc ion sources", in The Physics and Technology of Ion Sources (2 ${ }^{\text {nd }}$ Edition), I. G. Brown, Ed., Berlin: Wiley-VCH, 2004, Ch. 13.

[19] E. M. Oks, "Development of vacuum are ion sources for heavy ion accelerator injectors and ion implantation technology", Rev. Sci. Instrum., vol. 69, no. 2, pp. 776-781, 1998.

[20] I. G. Brown and X. Godechot, "Vacuum arc ion charge state distributions", IEEE Trans. Plasma Sci., vol. 19, no. 5, pp. 713-717, 1991.

[21] A. Anders, "Ion charge state distributions of vacuum arc plasmas: The origin of species", Phys. Rev. E, vol. 55, pp. 969-981, 1997.

[22] A. Anders, G. Yushkov, E. Oks , A. Nikolaev, and I. Brown, "Ion charge state distributions of pulsed vacuum arc plasmas in strong magnetic fields", Rev. Sci. Instrum., vol. 69, no. 3, pp. 1332-1335, 2000. 
[23] A. S. Bugaev, E. M. Oks, G. Yu. Yushkov, A. Anders and I. G. Brown, "Enhanced ion charge states in vacuum arc plasmas using a 'current spike' method",

Rev. Sci. Instrum., vol. 71, no. 2, pp. 701-703, 2000.

[24] T. V. Kulevoy, V. A. Batalin, A. Hershkovitch, B. M. Johnson, A. A. Kolomiets, R. P. Kuibeda, D. A. Kashinky, V. G. Kuzmitchev, V. I. Pershin, S. V. Petrenko, D. N. Seleznev, and E. M. Oks, "Enhancement of ion beam charge states by adding a second anode to metal vapor vacuum arc ion source", Nucl. Instrum. Meth. Phys. Res. A, vol. 552, no. 3, pp 171-177, 2004.

[25] V. Batalin, A. Bugaev, V. Gushenets, G. Yushkov, E. Oks, T. Kulevoy, A. Hershcovitch, B. Johnson et al, "Electron beam enhancement of the metal vapor vacuum arc ion source", J. Appl. Phys., vol. 92, no. 5, pp. 2884-2889, 2002.

[26] A. V. Vodopyanov, S. V. Golubev, V. G. Zorin, S. V. Razin, A. V. Vizir, A. G. Nikolaev, E. M. Oks, and G. Yu. Yushkov, "Multiple ionization of metal ions by ECR heating of electrons in vacuum arc plasmas", Rev. Sci. Instrum., vol. 75, no. 5, pp. 1888-1890, 2004.

[27] E. M. Oks, "Generation of multiply charged ions in vacuum arc plasmas", IEEE Trans. Plasma Sci., vol. 30, no. 1, pp. 202-207, 2002.

[28] G. A. Mesyats, "Ecton mechanism of the vacuum arc cathode spot" , IEEE Trans. Plasma Sci., vol.23, no. 6, pp. 879-883, 1995.

[29] I. G. Brown, X. Godechot, P. Spädtke, H. Emig, D. M. Rück, and B. H. Wolf, "Review of Mevva ion source performance for accelerator injection", Proc. IEEE Particle Accelerator Conf, IEEE Conf. Proc. Series. 91CH3038-7 (1991), p. 1943-1945.

[30] I. G. Brown, "Vacuum arc ion sources for particle accelerators and ion implantation", IEEE Trans. Plasma Sci., vol. 21, no. 5, pp. 537-546, 1993.

[31] S. Humphries, Jr., C. Burkhart, S. Coffey, G. Cooper, L. K. Len, M. Savage, D. M. Woodall, H. Rutkowski, H. Oona, and R. Shurter, "Grid-controlled extraction of pulsed ion beams", J. Appl. Phys., vol. 59, no. 6, pp. 1790-1798, 1986. 
[32] E. Oks, P. Spädtke, H. Emig, and B. H. Wolf, "Ion beam noise reduction method for the MEVVA ion source", Rev. Sci. Instrum., vol. 65, no. 10, pp. 3109-3112, 1994.

[33] E. Oks, G. Yushkov, I. Litovko, A. Anders, and I. Brown, "Further development of low noise vacuum arc ion source", Rev. Sci. Instrum., vol. 73, no. 2, pp. 735-737, 2002.

[34] R. Hollinger, M. Galonska, and P. Spädtke, "Development of a vacuum arc ion source for injection of high current uranium ion beams into the UNILAC at GSI", Rev. Sci. Instrum., vol. 75, no. 5, pp. 1595-1597, 2004.

[35] A. Anders, I. G. Brown, R. A. MacGill, and M. R. Dickinson, "'Triggerless' triggering of vacuum arcs", J. Phys. D: Appl. Phys., vol. 31, no. 5, pp. 584-587, 1998.

[36] A. Anders, J. Schein, and N. Qi, "Pulsed vacuum-arc ion source operated with a "triggerless" arc initiation method", Rev. Sci. Instrum., vol. 71, no. 2, pp. 827-829, 2000.

[37] A. G. Nikolaev, G. Yu. Yushkov, E. M. Oks, R. A. MacGill, M. R. Dickinson, and I. G. Brown, "Vacuum arc trigger systems based on E×B discharges", Rev. Sci. Instrum., vol. 67, no. 9, pp. 3095-3098, 1996.

[38] E. M. Oks, G. Yu. Yushkov, P. J. Evans, A. Oztarhan, I. G. Brown, M. R. Dickinson, F. Liu, R. A. MacGill, O. R. Monteiro, and Z. Wang, "Hybrid gas-metal co-implantation with a modified vacuum arc ion source", Nucl. Instrum. Meth. Phys. Res. B, vol. 127/128, pp. 782-786, 1997.

[39] P. Spädtke, H. Emig, B. H. Wolf, and E. M. Oks, "Influence of gas added to the MEVVA discharge on the extracted ion beam", Rev. Sci. Instrum., vol. 65, no. 10, pp. 3113-3118, 1994.

[40] G. Y. Yushkov, R. A. MacGill, and I. G. Brown, "Mevva ion source operated in purely gaseous mode", Rev. Sci. Instrum, vol. 75, no. 5, pp. 1582-1584, 2004.

[41] G. Y. Yushkov and A. Anders, "Effect of the pulse repetition rate on the composition and ion charge-state distribution of pulsed vacuum arcs", IEEE Trans. Plasma Sci., vol. 26, no. 2, pp. 220-226, 1998. 
[42] A. Anders and G. Yushkov, "Ion flux from vacuum arc cathode spots in the absence and presence of a magnetic field", J. Appl. Phys. vol. 91, no. 8, pp. 4824-4832, 2002.

[43] G. A. Mesyats and S. A. Barengol'ts, "Mechanism of anomalous ion generation in vacuum arcs", Physics-Uspekhi, vol. 45, no. 10, pp. 1001-1018, 2002.

[44] G. Y. Yushkov, A. S. Bugaev, I. A. Krinberg, and E. M. Oks, "On the mechanism of ion acceleration in vacuum arc discharge plasmas", Doklady Physics, vol. 46, no. 5, pp. 307-309, 2001.

[45] V. I. Gushenets, E. M. Oks, G. Yu. Yushkov, and N. G. Rempe, "Current status of plasma emission Electronics: I. Basic physical processes", Laser and Particle Beams, vol. 21, no. 2, pp. 123-138, 2003.

[46] A. S. Bugaev, V. I. Gushenets, A. G. Nikolaev, E. M. Oks, and G.Y. Yushkov, "Study of directed ion velocities in a vacuum arc by an emission method", Tech. Phys., vol. 45, no. 9, pp.1135-1140, 2000.

[47] G. Y. Yushkov, A. Anders, E. M. Oks, and I. G. Brown, "Ion velocities in vacuum arc plasmas", J. Appl. Phys., vol. 88, no.10, pp. 5618-5622, 2000.

[48] A. Anders, B. Yotsombat, and R. Binder, "Correlation between cathode properties, burning voltage, and plasma parameters of vacuum arcs", J. Appl. Phys., vol. 89, no. 12, pp. 7764-7771, 2001.

[49] C. W. Kimblin, "Erosion and ionization in the cathode spot regions of vacuum arcs", J. Appl. Phys., vol. 44, no. 7, pp. 3074-3081, 1973.

[50] C. W. Kimblin, "Cathode spot erosion and ionization phenomena in the transition from vacuum to atmospheric pressure arcs", J. Appl. Phys., vol. 45, no. 12, pp. 5235-5244, 1974.

[51] See, for instance, J. M. Lafferty, Ed., Vacuum Arcs - Theory and Application, New York: Wiley, 1980.

[52] A. Anders, E. M. Oks, G. Yu. Yushkov, K. P. Savkin, I. G. Brown, and A. G. Nikolaev, "Measurements of the total ion flux from vacuum arc cathode spots", IEEE Trans. Plasma Sci., vol. 33, 2005 (to be published). 
[53] R. A. MacGill, A. Vizir, and I. G. Brown, "On the use of magnetic buckets for ion beam profile tailoring", Rev. Sci. Instrum. vol. 71, no. 2, pp. 672-674, 2000.

[54] I. G. Brown, A. Anders, S. Anders, M. R. Dickinson, R. A. MacGill, and E. M. Oks, "Recent advances in vacuum are ion sources", Surf. Coat. Technol., vol. 84, no. 1-3, pp. 550-556, 1996.

[55] E. M. Oks and I. G. Brown, "Electron beam extraction from a broad-beam vacuum-arc metal plasma source", IEEE Trans. Plasma Sci., vol. 26, no. 5, pp. 1562-1565, 1998.

[56] N. Akbas, A. Oztarhan, O. R. Monteiro, and I.G. Brown, "Investigation of the tribology of Zr ion implanted tool steel", Wear, vol. 252, no. 7-8, pp. 540-545, 2002.

[57] K. M. Yu, B. Katz, I. C. Wu, and I. G. Brown, "Formation of iridium silicide layer by high dose iridium ion implantation into silicon", Nucl. Instrum. Meth. Phys. Res. B, vol. 58, no. 1, pp. 27-33, 1991.

[58] W. M. Jadwisienczak, H. J. Lozykowski, I. Berishev, A. Bensaoula, and I. G. Brown, "Visible emission from AlN doped with Eu and Tb ions", J. Appl. Phys., vol. 89, no. 8, pp. 4384-4390, 2001.

[59] M. I. Ignatius, N. Sawhney, A. Gupta, B. Thibadeau, O. R. Monteiro, and I.G. Brown, "Bioactive surface coatings for nanoscale instruments: Effects on CNS neurons", J. Biomed. Mat. Res., vol. 40, pp. 264-274, 1998.

[60] A. Anders and J. W. Kwan, "Arc-discharge ion sources for heavy ion fusion", Nucl. Instrum. Meth. Phys.Res. A, vol. 464, no. 1-3, pp. 569-575, 2001.

[61] I. G. Brown, A. Anders, M. R. Dickinson, R. A. MacGill, and O. R. Monteiro, Recent advances in surface processing with metal plasma and ion beams, Surf. Coat. Technol., vol. 112, no.1-3, pp. 271-277, 1999.

[62] E. Oks and I. Brown, "Vacuum arc ion sources", in The Physics and Technology of Ion Sources, $2^{\text {nd }}$ edition, I. G. Brown Ed., Berlin: Wiley-VCH, 2004. pp. 257-284.

[63] A. S. Bugaev, V. I. Gushenets, A. G. Nikolaev, E. M. Oks, K. P. Savkin, P. M. Schanin, 
G. Yu. Yushkov, and I.G. Brown, "Production of gas and metal ion beams from vacuum arc ion sources", in Emerging Applications of Vacuum-Arc-Produced Plasma, Ion and Electron Beams, E. Oks and I. Brown, Eds., Dordrecht: Kluwer Academic, 2002. pp. 79-90.

[64] A. I. Ryabchikov, I. B. Stepanov, S. V. Dektjarev, E. I. Lukonin, and I. A. Shulepov, "Very broad beam vacuum arc ion and plasma sources with extended large area cathodes", Rev. Sci. Instrum., vol. 71, no. 2, pp. 704-706, 2000.

[65] A. I. Ryabchikov, I. B. Stepanov, S. V. Dekjarev, and O. V. Sergeev, "Vacuum arc ion and plasma source Raduga 5 for materials treatment", Rev. Sci. Instrum., vol. 69, no. 2, pp. 893-895, 1998.

[66] A. Oztarhan, I. Brown, C. Bakkaloglu, G. Watt, P. Evans, E. Oks, A. Nikolaev, and Z. Tek, "Metal vapor vacuum arc ion implantation facility in Turkey", Surf. Coat. Technol., 2005, (to be published).

[67] A. D. Liu, H. X. Zhang, and T. H. Hang, "Mevva ion source and its industrial application at Bejing Normal University", Surf. Coat. Technol., (submitted for publication).

[68] H. Zhang, X. Zhang, F. Zhou, S. Zhang, Q. Li, and Z. Han, "The Beijing metal vapor vacuum arc ion source program", Rev. Sci. Instrum., vol. 65, no. 10, pp. 3088-3090, 1994.

[69] Y. Zhang, T. Zhang, Z. Xiao, and H. J. Whitlow, "Sputtering transients for some transition elements during high-fluence MEVVA implantation of silicon", Nucl. Instrum. Meth. Phys. Res. B, vol. 171, no. 4, pp. 427-435, 2001.

[70] Y. Wu, T. Zhang, Y. Zhang, H. Zhang, X. Zhang, and G. Zhou, "Behavior of PET implanted by Ti, Ag, Si and C ion using MEVVA implantation", Nucl. Instrum. Meth. Phys. Res. B, vol. 173, pp. 292-298, 2001

[71] Huang Yan, Hei Zukun, Gong Zexiang, and Li Guoqing, "Substructure variation of austenitic stainless steel affected by W ion implantation", Dalian Ligong Daxue Xuebao (Journal of Dalian University of Technology), vol. 37, no. 2, pp.199-203, 1997. 
[72] K. Baba, S. Nagata, R. Hatada, T. Daikoku, and M. Hasaka, "The effects of Ti implantation on corrosion and adhesion of TiN coated stainless steel", Nucl. Instrum. Meth. Phys. Res. B, vol. 80/81, pt. 1, pp. 297-300, 1993.

[73] H. Reich, P. Spädtke, and E.M. Oks, "Metal vapor vacuum arc ion source development at GSI", Rev. Sci. Instrum., vol. 71, no. 2, pp. 707-709, 2000

[74] F. Heymach, M. Galonska, R. Hollinger, K. Leible, P. Spädtke, and M. Stork, "Technical design of the Mevva ion source at GSI and results of a long uranium beam time period", in Emerging Applications of Vacuum-Arc-Produced Plasma, Ion and Electron Beams, E. Oks and I. Brown, Eds., Dordrecht: Kluwer Academic, 2002. pp. 59-65.

[75] R. Hollinger, M Galonska, and P. Spädtke, "Development of a vacuum arc ion source for injection of high current uranium ion beams into the UNILAC at GSI", Proc. 20th Intern. Symp. on Discharges and Electrical Insulation in Vacuum, Yalta, Ukraine, September 2004, (Cat. No. 04CH37565), vol. 2, pp. 547-549. 
TABLE I

PARAMETERS OF THE BNU MEVVA-50 ION IMPLANTER

\begin{tabular}{l|l}
\hline Time-averaged ion beam current & $50 \mathrm{~mA}$ \\
\hline Extraction voltage & up to $50 \mathrm{kV}$ \\
\hline Arc current & $80-200 \mathrm{~A}$ \\
\hline Beam size (diameter) & $50 \mathrm{~cm}$ \\
\hline Pulse length & $2.4 \mathrm{~ms}$ \\
\hline Repetition rate & $0-25 \mathrm{pps}$ \\
\hline Vacuum chamber diameter & $1.2 \mathrm{~m}$ \\
\hline Vacuum chamber pressure & up to $4 \times 10^{-4}$ torr \\
\hline
\end{tabular}




\section{TABLE II}

\section{PARAMETERS OF THE BNU MEVVA-100 ION IMPLANTER}

\begin{tabular}{l|l}
\hline Time-averaged ion beam current & $100 \mathrm{~mA}$ \\
\hline Extraction voltage & up to $50 \mathrm{kV}$ \\
\hline Beam size (diameter) & $80 \mathrm{~cm}$ \\
\hline Pulse length & $3.3 \mathrm{~ms}$ \\
\hline Repetition rate & $0-33 \mathrm{pps}$ \\
\hline Vacuum chamber diameter & $2.0 \mathrm{~m}$ \\
\hline Vacuum chamber pressure & up to $4 \times 10^{-4}$ torr \\
\hline Cathode lifetime & $>8$ hours \\
\hline
\end{tabular}


TABLE III

\section{GSI VARIS ION SOURCE AND ION BEAM PARAMETERS}

\begin{tabular}{l|l}
\hline Ion species & Uranium \\
\hline Ion charge state distribution & $\mathrm{U}^{3+}=16 \%, \mathrm{U}^{4+}=67 \%, \mathrm{U}^{5+}=14 \%, \mathrm{U}^{6+}=3 \%$ \\
\hline Extracted ion beam current & $156 \mathrm{~mA} @ 35 \mathrm{kV}$ \\
\hline Accelerated ion beam current & $55 \mathrm{~mA} @ 131 \mathrm{kV}$ \\
\hline Analyzed $\mathrm{U}^{4+}$ ion beam current & $25 \mathrm{~mA}$ \\
\hline Pulse length / repetition rate & $0.6 \mathrm{~ms} / 1 \mathrm{pps}$ \\
\hline Extraction system & $13 \times 3 \mathrm{~mm}, \mathrm{multi}$-aperture \\
\hline$\varepsilon_{\mathrm{X} . \mathrm{V}}(156 \mathrm{~mA} @, 35 \mathrm{kV})$ & $200 \pi \mathrm{mm} \mathrm{rad}$ \\
\hline$\varepsilon_{\mathrm{X} . \mathrm{V}}(55 \mathrm{~mA} @ 131 \mathrm{kV})$ & $350 \pi \mathrm{mm} \mathrm{rad}$ \\
\hline$\varepsilon_{\mathrm{X} . \mathrm{V}}($ after separation, $15 \mathrm{~mA})$ & $100 \pi \mathrm{mm} \mathrm{rad}$ \\
\hline Noise, full beam / analysed (rms) & $< \pm 4 \% / \pm 5 \%$ \\
\hline Pulse-to-pulse stability & Better than $80 \%$ \\
\hline Voltage breakdowns (extractor grids) & 2 per day \\
\hline Cathode lifetime & 12 hours @ $0.6 \%$ duty \\
\hline Lifetime of the ion source (between maintenance) & 7 days for SIS inj. $(0.2 \% \mathrm{dc})$ \\
\hline
\end{tabular}




\section{$\underline{\text { Figure Captions }}$}

Fig. 1 Simplified schematic of the LBNL Mevva II ion source.

Fig. 2 Schematic of the HCEI ion source set-up showing the configuration for electron beam heating, current spike generation, and the time-of-flight charge state spectrometer. 1 - ion source cathode, 2 - solenoid, 3 - anode, 4 - beam extraction and acceleration system, 5 - time-of-flight gate, 6 - Faraday cup, 7 - electron beam gun. Power supplies for 8 - arc current spike, 9 - vacuum arc, 10 - accelerating voltage, 11 - time-of-flight gate pulse. 12 - oscilloscope

Fig. 3 (a) Uranium ion beam (all charge states) current pulse from the GSI Varis source measured $30 \mathrm{~cm}$ from the source extractor; $40 \mathrm{~mA} / \mathrm{div}$.

(b) Post-analysis $\mathrm{U}^{4+}$ beam at the RFQ entrance, a distance of $12 \mathrm{~m}$ from the source; $5 \mathrm{~mA} / \mathrm{div}$.

Sweep speed is $100 \mu \mathrm{s} / \mathrm{div}$.

Fig. 4 Metal-to-gas ion beam composition fraction as a function of nitrogen gas pressure, for a hybrid Ti-N ion beam formed using the LBNL Mevva-V ion source.

Fig. 5 Drift velocity of vacuum arc plasma ions as a function of atomic number of the ion species (cathode material) used. Also plotted are velocities calculated from hydrodynamic models as described in the text; upper line Eq. (1), and lower line Eq. (2). 
Fig. 6 Mevva-V vacuum arc ion source as modified for measurement of ion erosion rate. $\mathrm{C}$ - cathode rod, TR - trigger, AM - anode mesh, COL - ion collector. The two connected collector electrodes COL1 and COL2 are parts of the ion extraction system when the ion source is used in its conventional mode.

Fig. 7 LBNL Mevva-V source, fitted with pulsed solenoid surrounding the arc region and with gas inlet feed.

Fig. 8 LBNL Mevva-V source, partly disassembled showing the 10-cm extractor grids on the left and the multiple cathode assembly on the right.

Fig. 9 Schematic of the Titan-3 ion source: 1 - gas feed inlet pipe; 2 - high-voltage cable; 3 - water cooling pipe; 4 - outer shield; 5 - constricted arc channel; 6 - vacuum arc cathode; 7 - high-voltage discharge chamber screen; 8 - tapered anode; 9 - ion beam formation electrodes.

Fig. 10 Photograph of the plasma discharge chamber the HCEI Titan-3 ion source.

Fig. 11 Schematic of the arc and filter region of the NPI broad beam source, which incorporates a large area dc cathode and a linear "venetian blind" macroparticle filter.

Fig. 12 Schematic of the electrical layout of the Izmir Mevva-V ion source.

Fig. 13 Photograph of the Izmir Mevva-V ion source facility.

Fig. 14 The BNU Mevva-50 implanter 
Fig. 15 BNU Mevva-100 implanter.

Fig. 16 Mevva ion implanter installation at the Industrial Technology Center of Nagasaki, Japan.

Fig. 17 GSI Varis ion source: 1 - Cathode flange, 2 - Cathode, 3 - Anode (stainless steel) 4-10 SmCo cusp magnets, 5 - Coil I, 6 - Coil II, 7 - Plasma electrode and grid, 8 - Screening electrode, 9 - Ground electrode, 10 - Insulators.

Fig. 18 Photograph of the partially-disassembled GSI Varis ion source. 


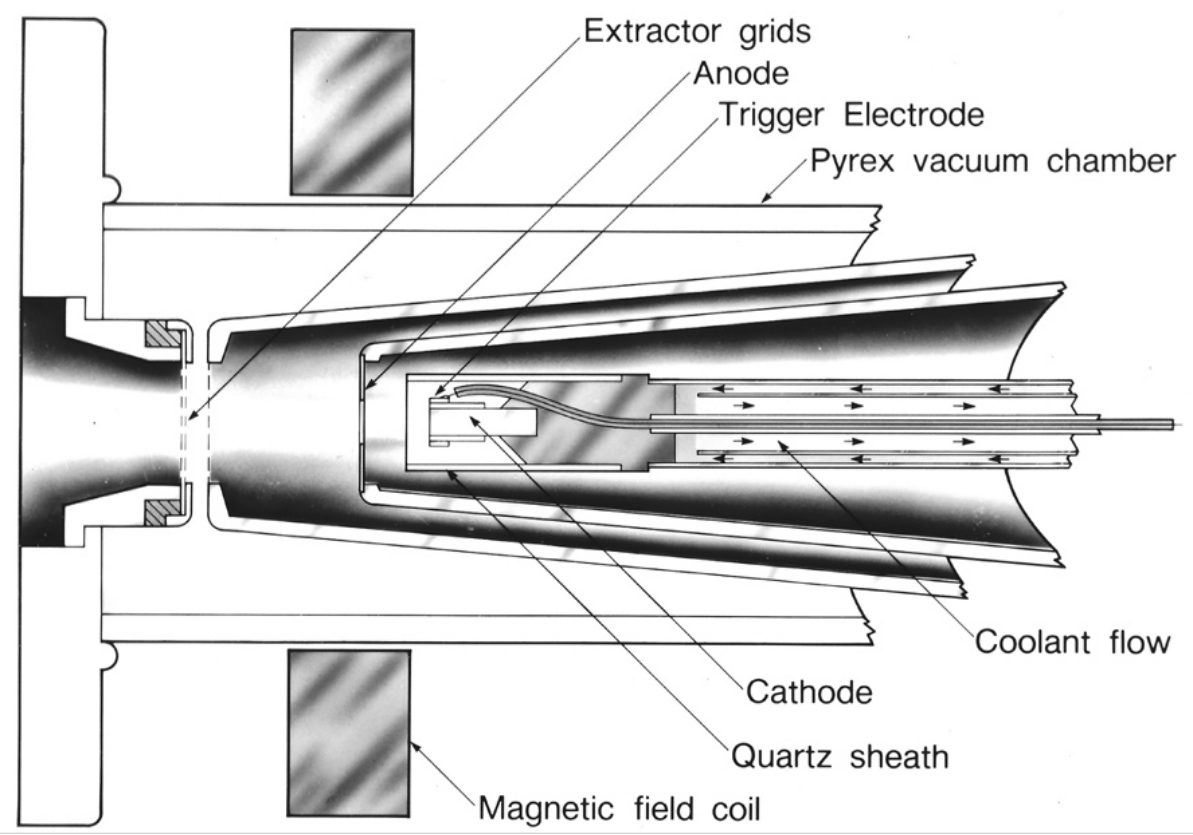

Fig. 1 


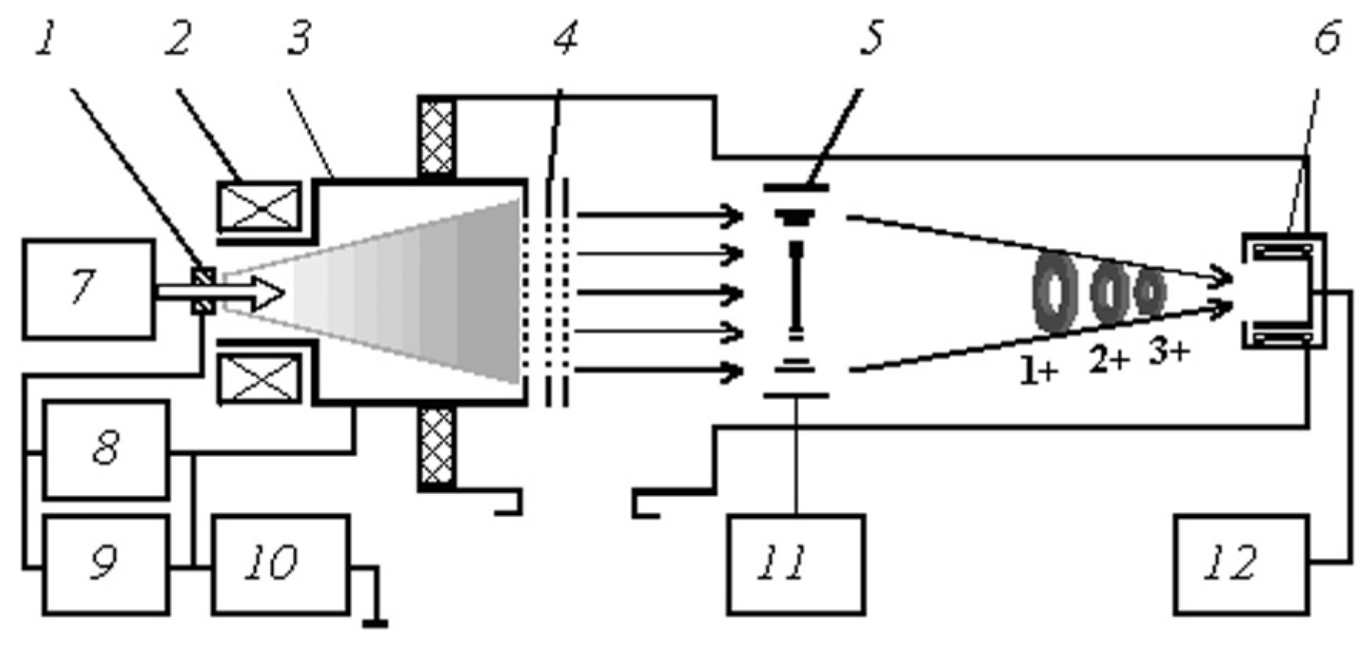

Fig. 2 


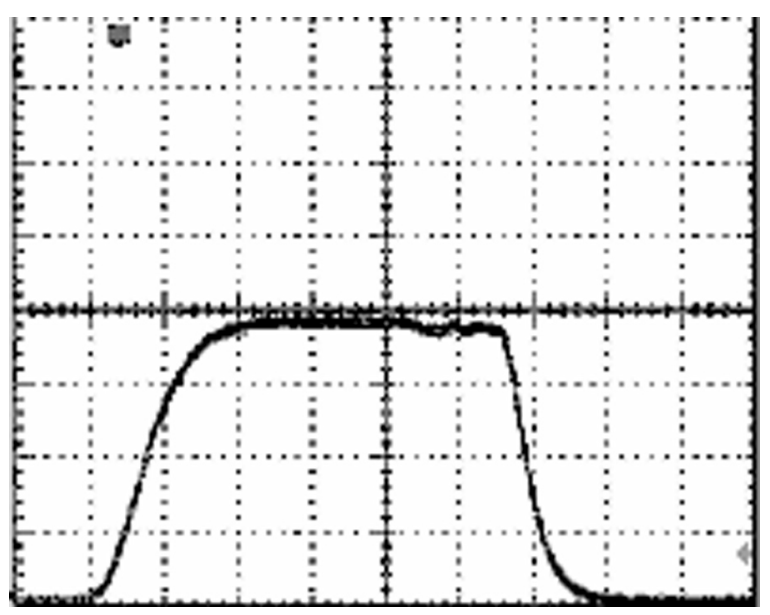

Fig. 3(a)

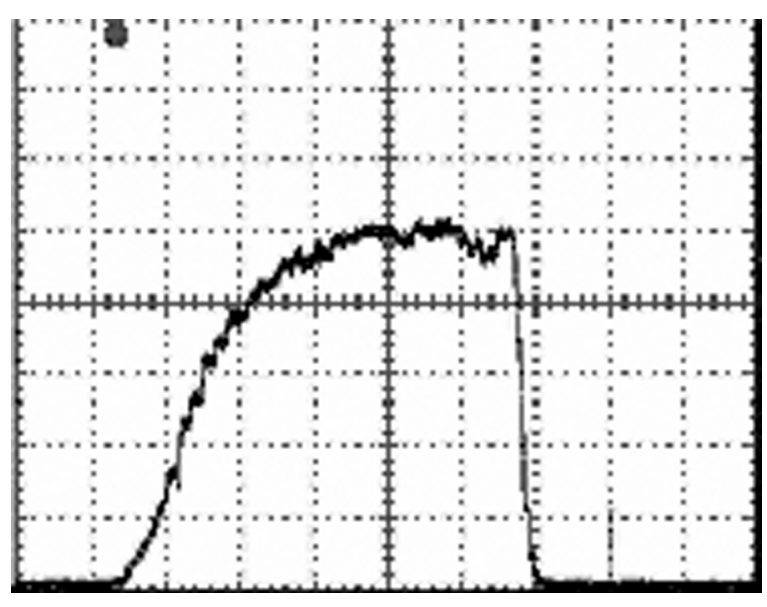

Fig. 3(b) 


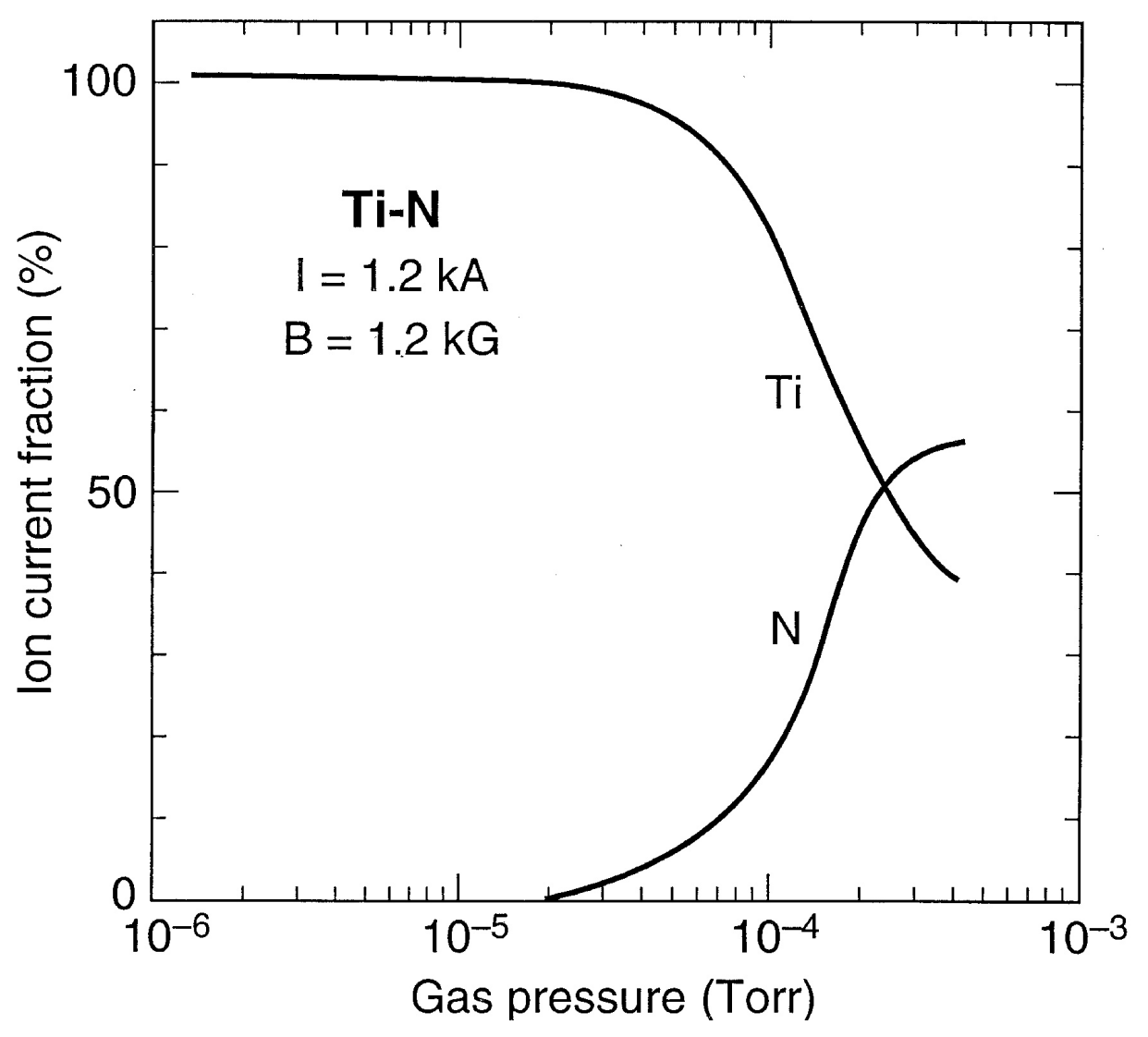

Fig. 4 


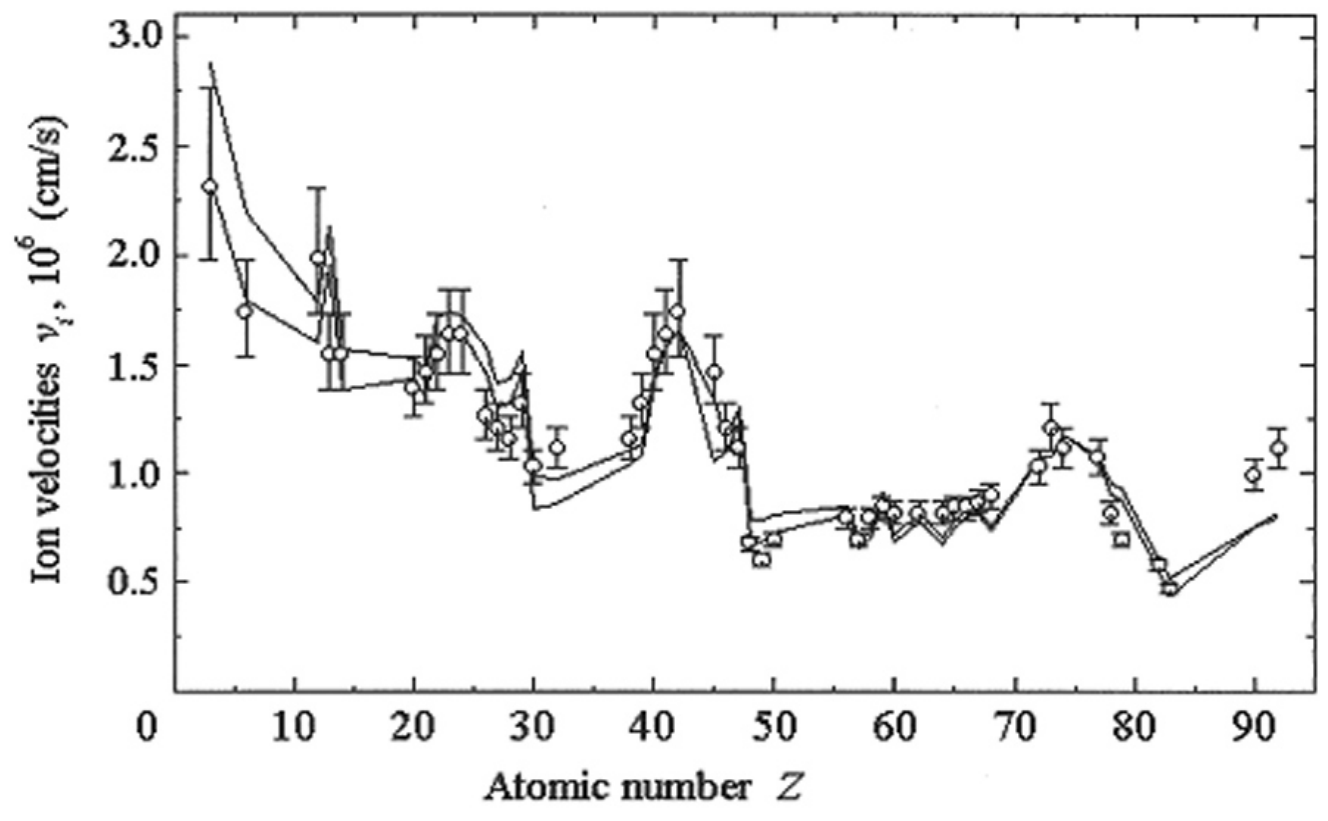

Fig. 5 


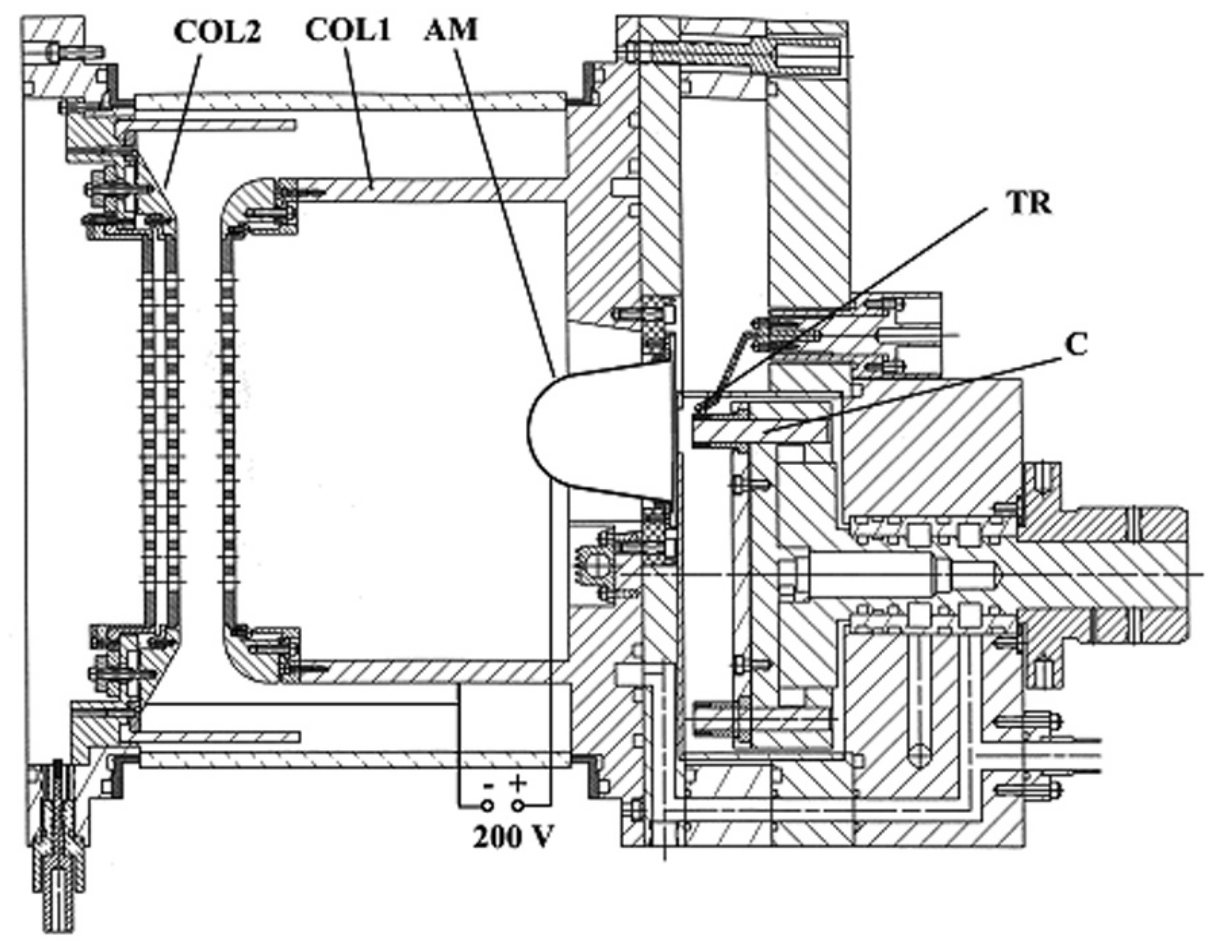

Fig. 6 


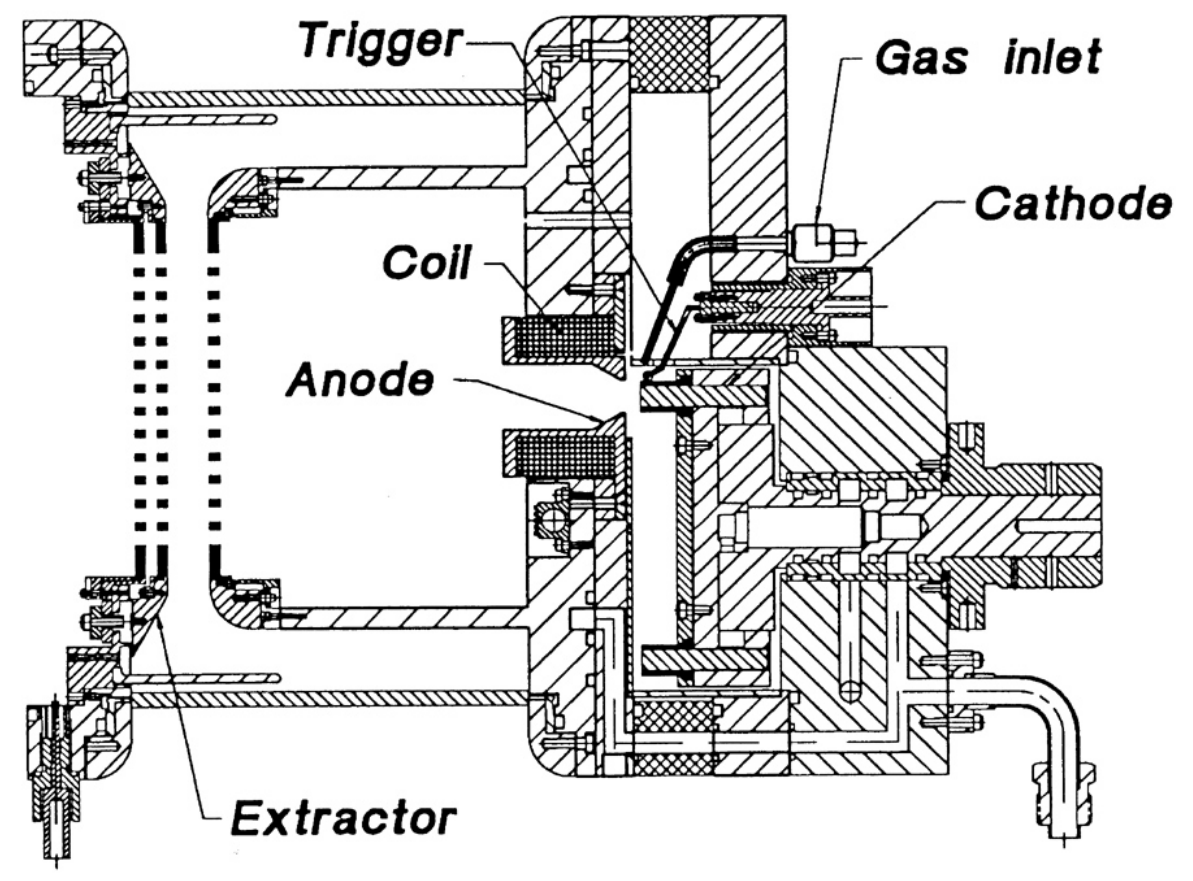

Fig. 7 


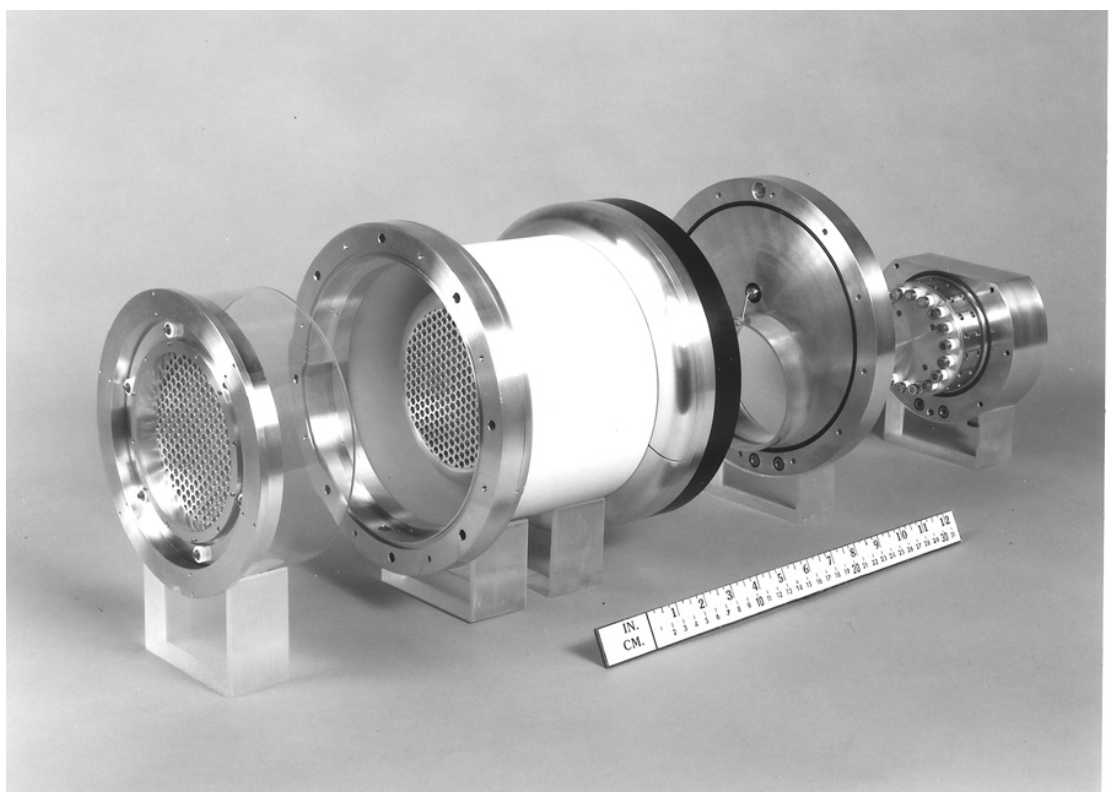

Fig. 8 


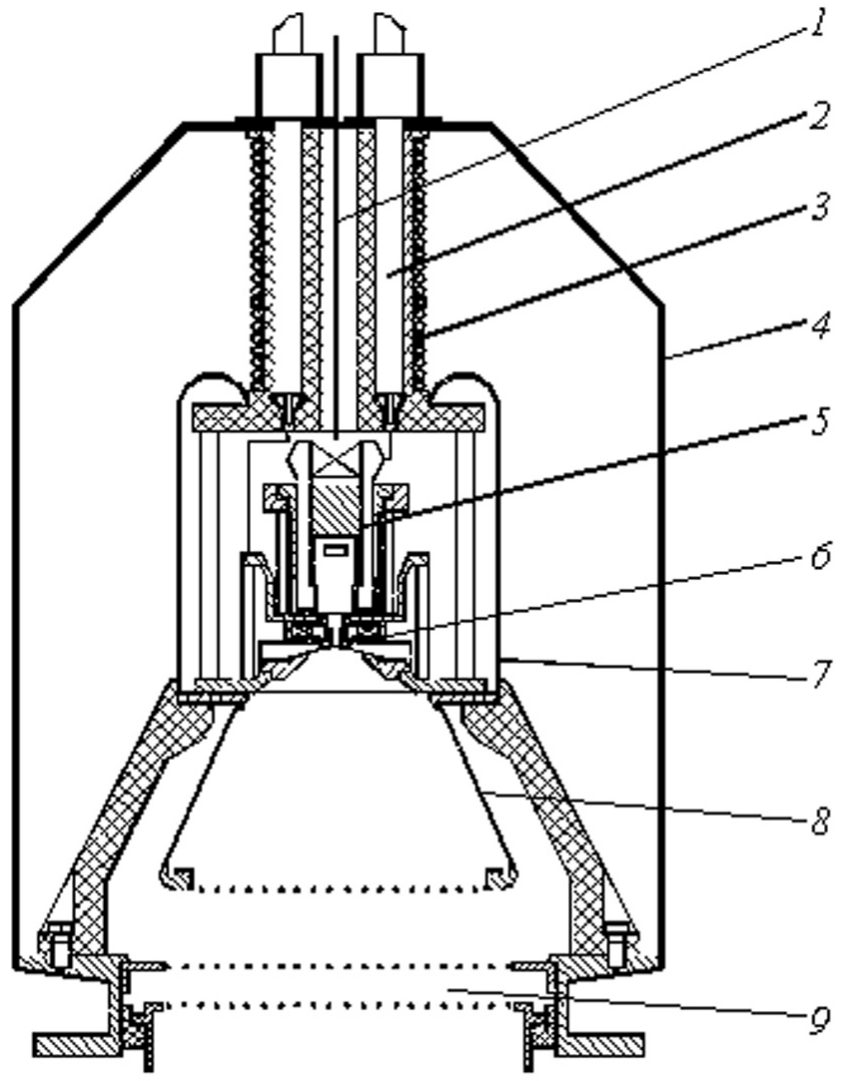

Fig 9 


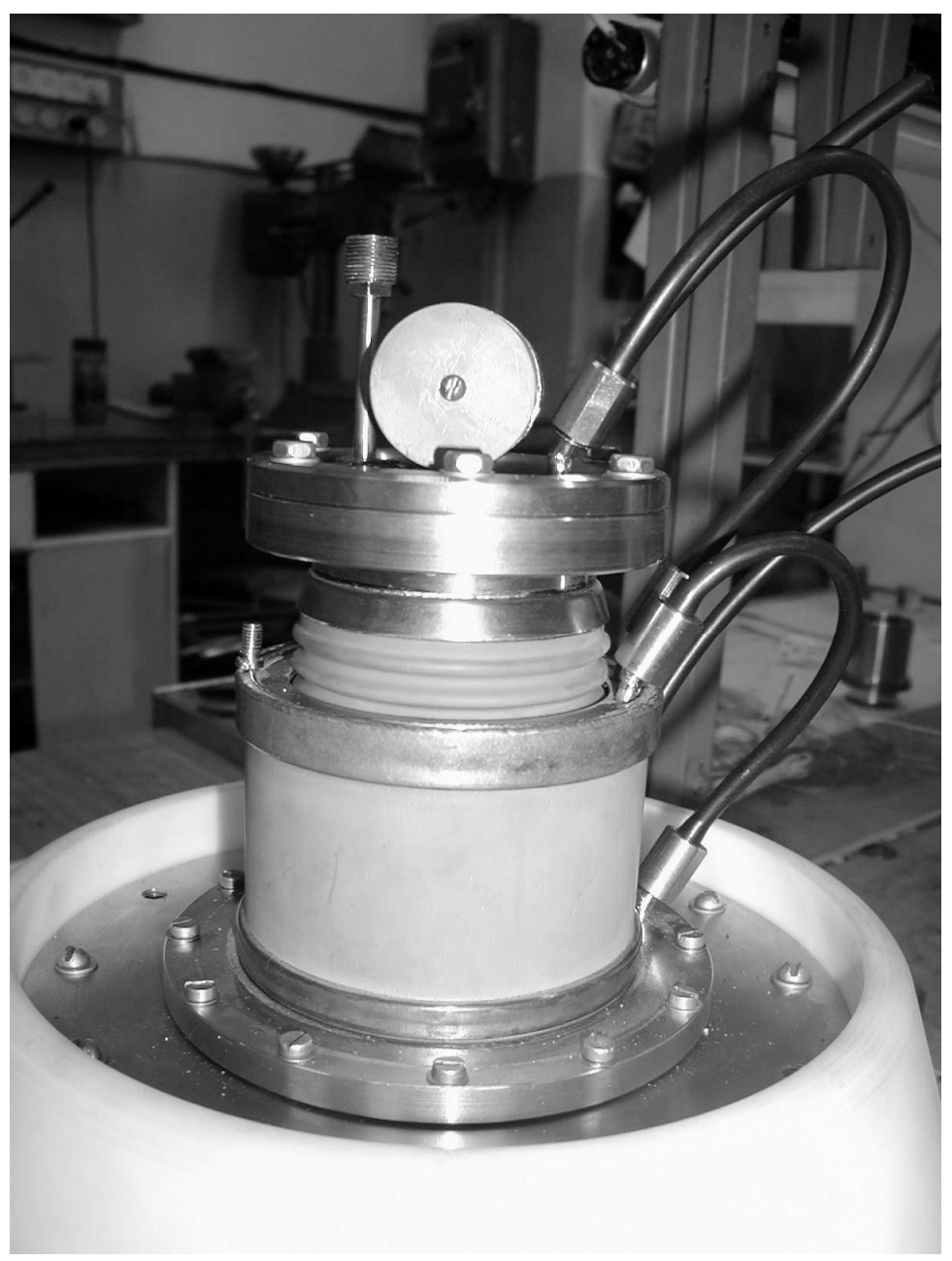

Fig. 10 


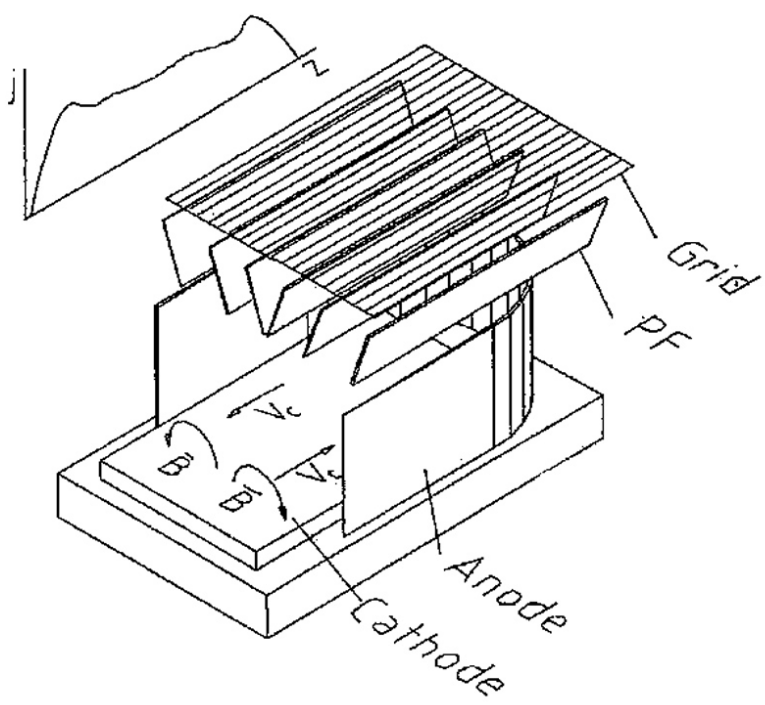

Fig. 11 


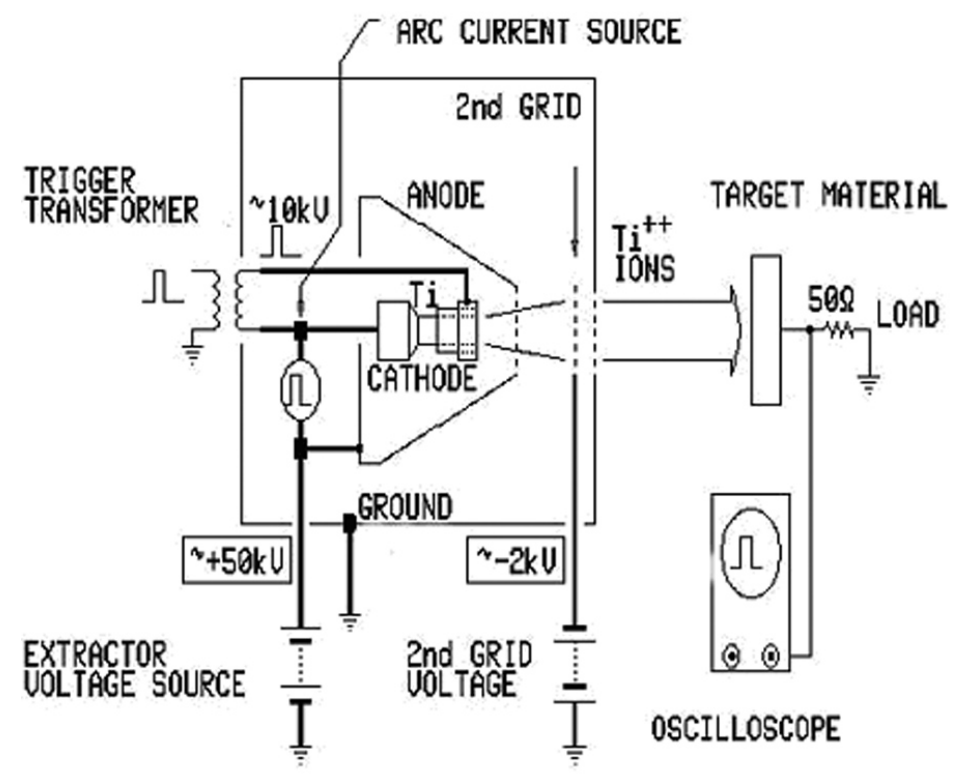

Fig. 12 


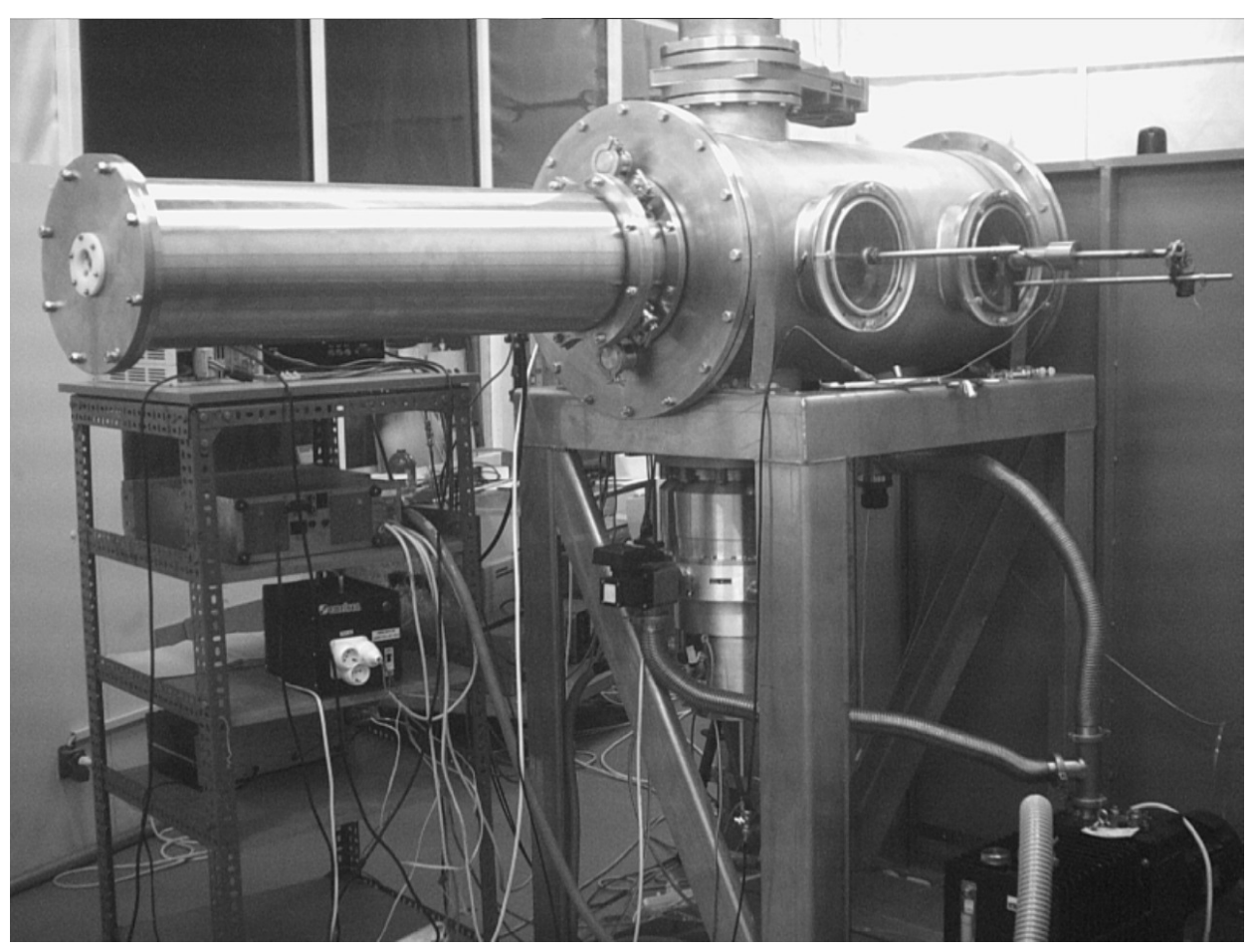

Fig. 13 


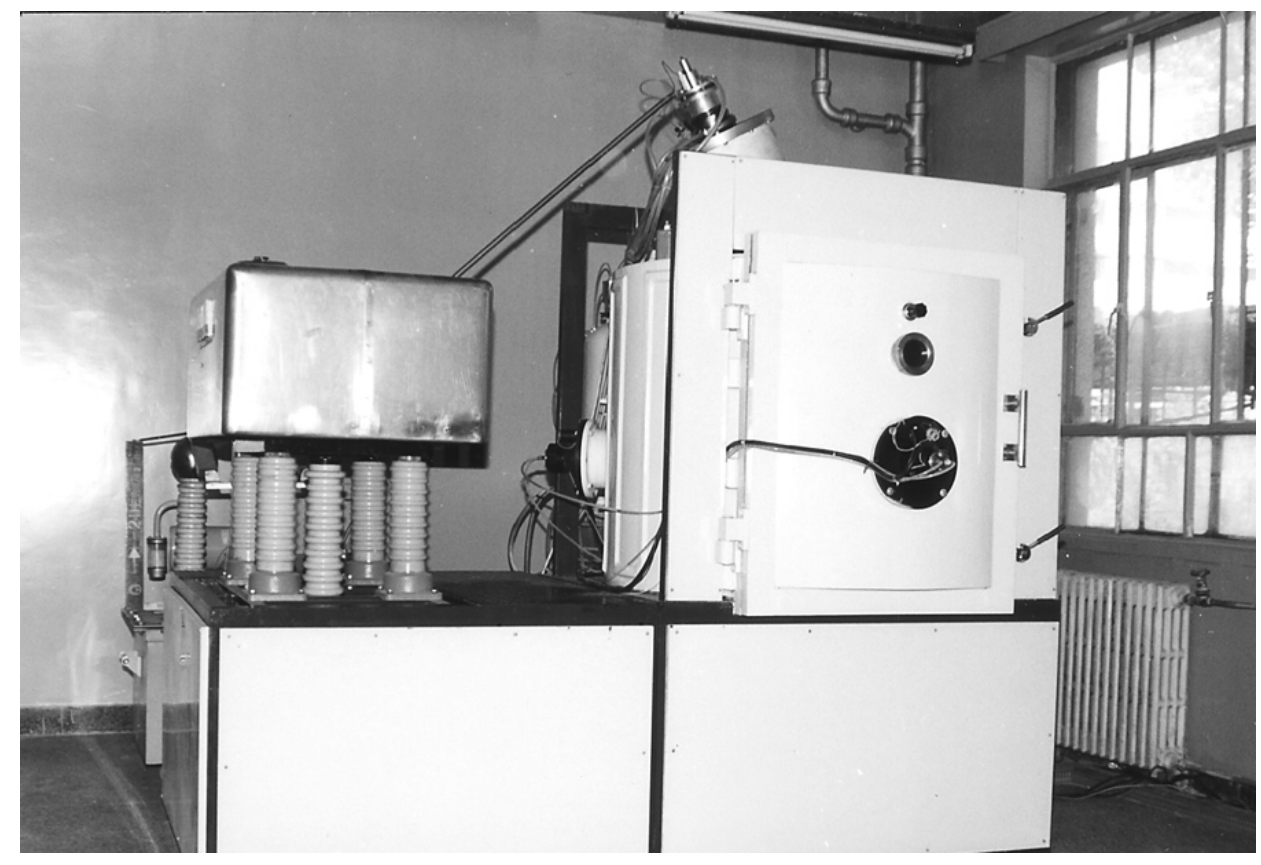

Fig. 14 


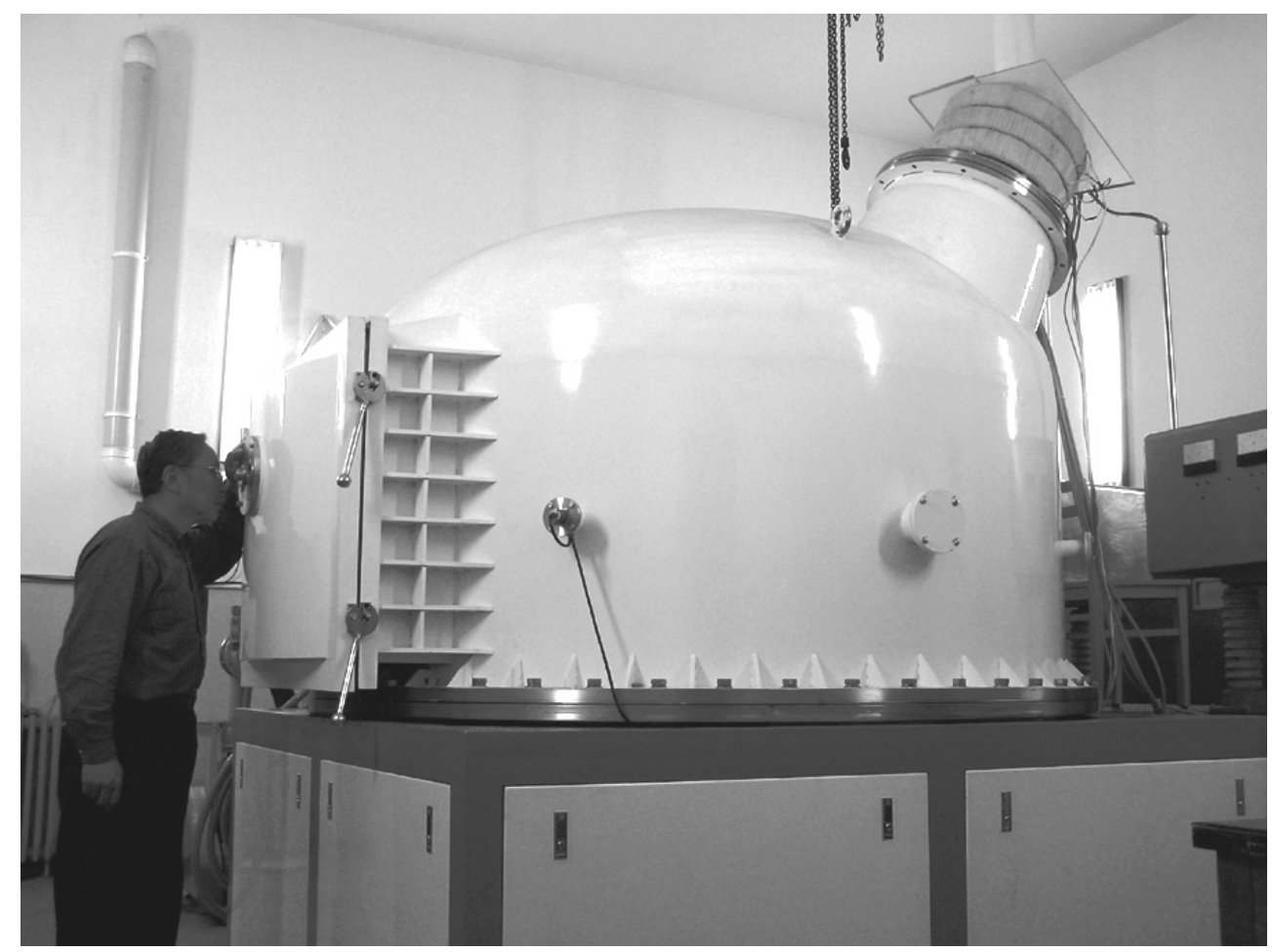

Fig. 15 


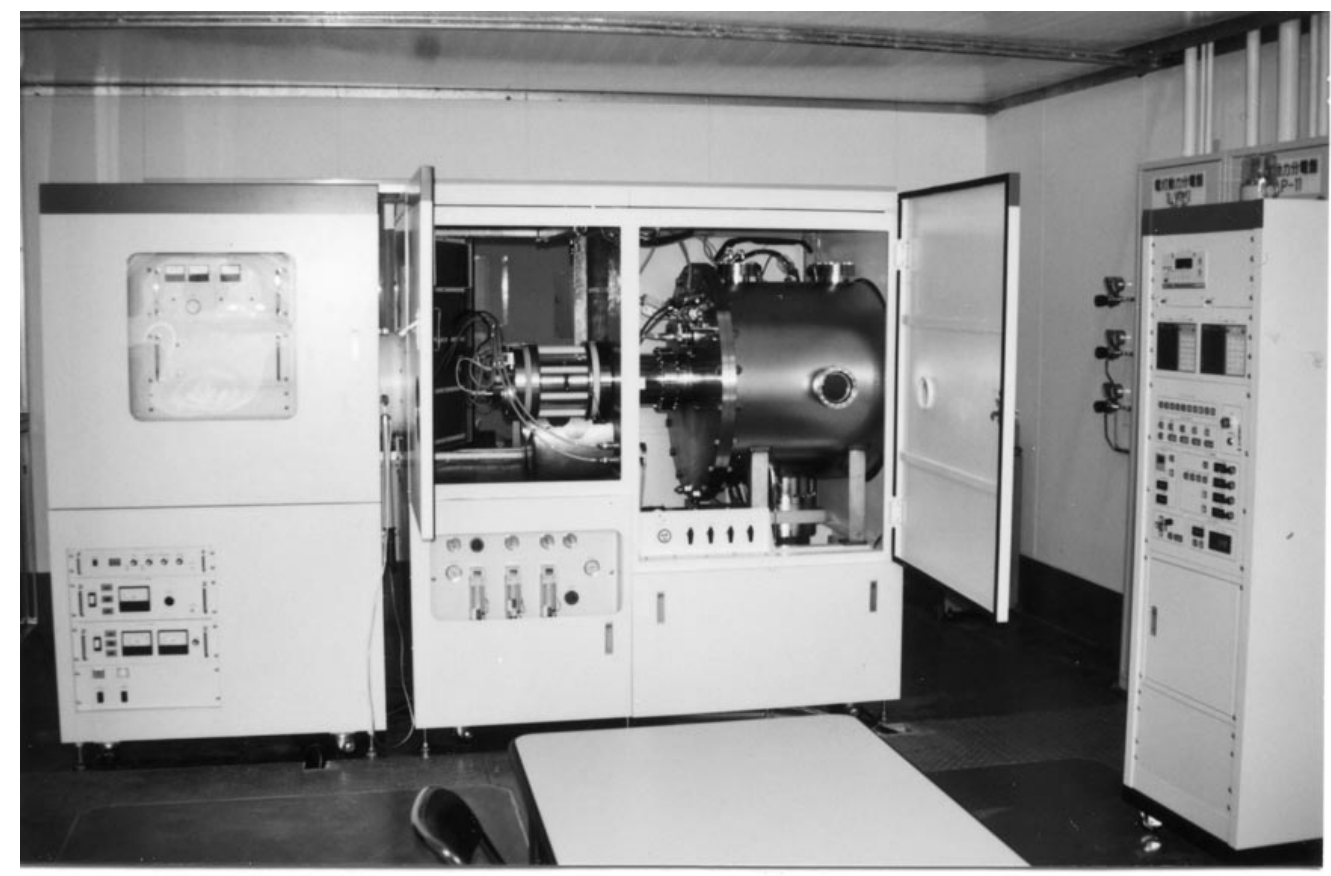

Fig. 16 


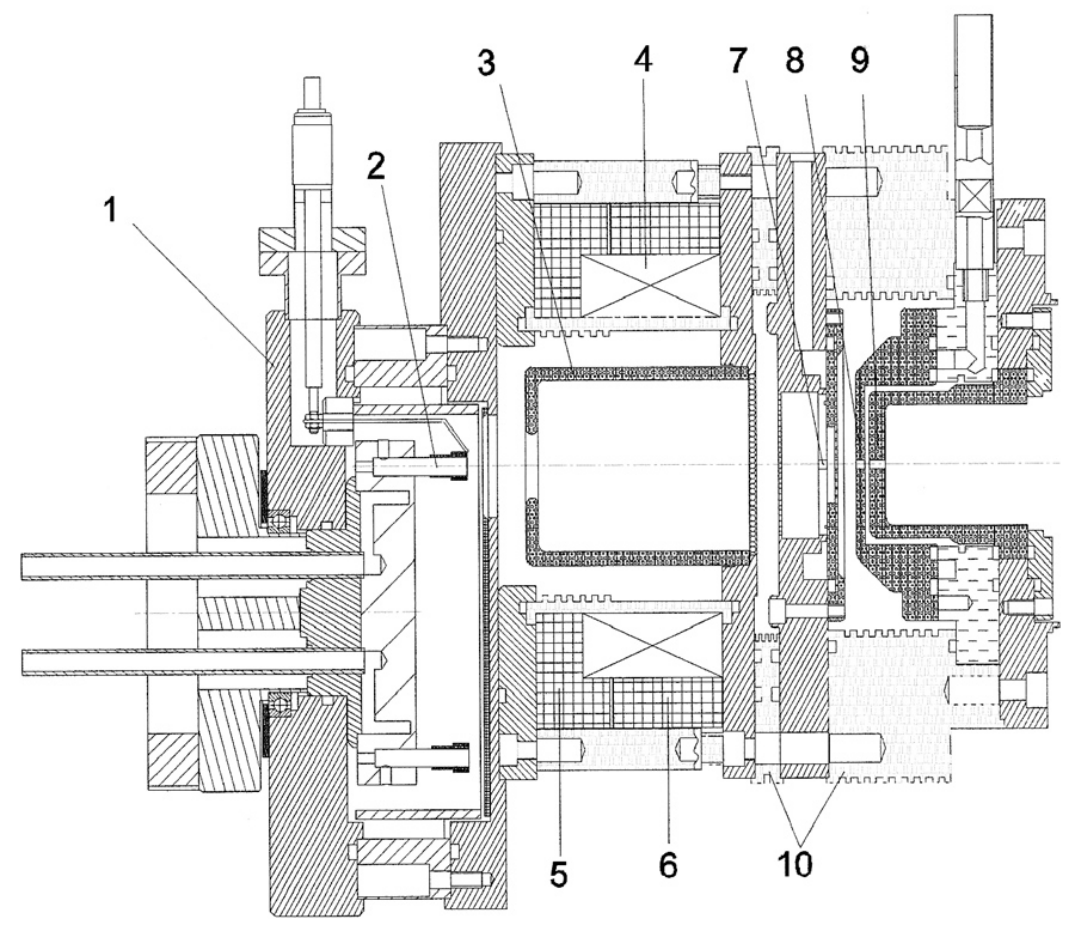

Fig. 17 


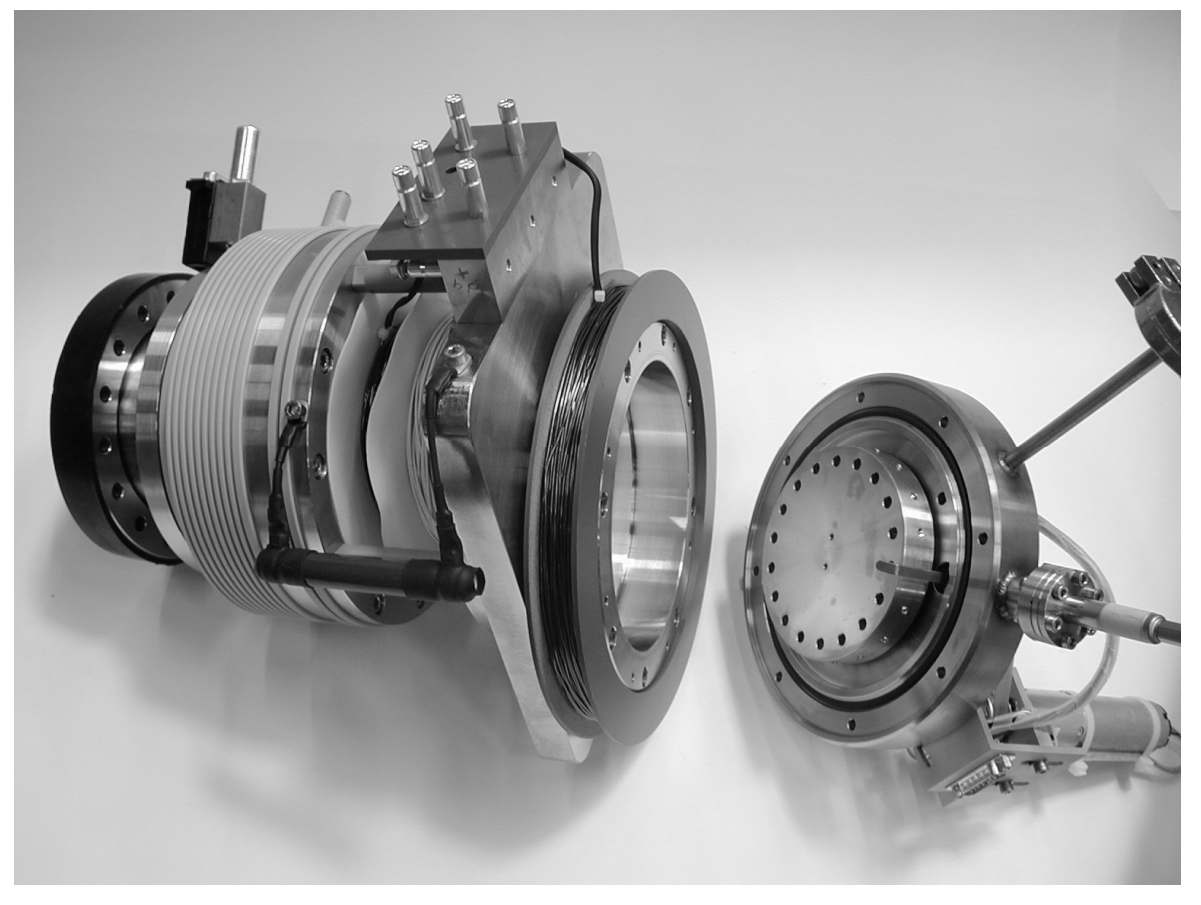

Fig. 18 